\title{
RNA-Mediated Regulation in Pathogenic Bacteria
}

\author{
Isabelle Caldelari ${ }^{1}$, Yanjie $\mathrm{Chao}^{2}$, Pascale Romby ${ }^{1}$, and Jörg Vogel ${ }^{2}$ \\ ${ }^{1}$ Architecture et Réactivité de I'ARN, Université de Strasbourg, CNRS, IBMC, F-67084 Strasbourg, France \\ ${ }^{2}$ Institute for Molecular Infection Biology (IMIB) and Zentrum für Infektionsforschung (ZINF), University \\ of Würzburg, 97080 Würzburg, Germany \\ Correspondence: joerg.vogel@uni-wuerzburg.de
}

Pathogenic bacteria possess intricate regulatory networks that temporally control the production of virulence factors, and enable the bacteria to survive and proliferate after host infection. Regulatory RNAs are now recognized as important components of these networks, and their study may not only identify new approaches to combat infectious diseases but also reveal new general control mechanisms involved in bacterial gene expression. In this review, we illustrate the diversity of regulatory RNAs in bacterial pathogens, their mechanism of action, and how they can be integrated into the regulatory circuits that govern virulencefactor production.

\begin{abstract}
Uuccessful host infection by pathogenic bacteria largely depends on the coordinated expression of a multitude of virulence factors and genes involved in the infection process. Over the last decade, much has been learned about the complexities of bacterial gene expression and it is now established that bacterial genes are regulated at many different levels, including and beyond transcriptional control at the DNA level. One class of macromolecules that have seen tremendous progress with respect to their regulatory scope and mechanisms is RNA. Regulatory RNAs are now recognized as important players in many physiological and adaptive responses in pathogenic bacteria (Gripenland et al. 2010; Papenfort and Vogel 2010). Some of them have been identified as previous missing links in the
\end{abstract}

regulatory pathways that allow bacteria to sense population density, to modulate and modify cell-surface properties, to fine-tune their metabolism during cell growth, and to regulate virulence gene expression. Most of these findings followed the pioneering discoveries of the unexpected large numbers of many small noncoding RNAs (sRNAs) and riboswitches in nonpathogenic model bacteria (Argaman et al. 2001; Wassarman et al. 2001; Mandal et al. 2003), which prompted many microbiologists to also systematically search for sRNAs in pathogenic bacteria. More recently, new technologies such as highthroughput RNA sequencing (RNA-seq) and high-density microarrays have facilitated the genome-wide detection of expressed RNAs in various pathogens and nonpathogens (Papen-

Editors: Pascale Cossart and Stanley Maloy

Additional Perspectives on Bacterial Pathogenesis available at www.perspectivesinmedicine.org

Copyright (C) 2013 Cold Spring Harbor Laboratory Press; all rights reserved; doi: 10.1101/cshperspect.a010298

Cite this article as Cold Spring Harb Perspect Med 2013;3:a010298 
I. Caldelari et al.

fort and Vogel 2010; Romby and Charpentier 2010; Papenfort et al. 2013a). Unlike 10 years ago when transposon insertions outside protein-coding regions were not deemed worth pursuing in virulence-factor screens, there is now a fast-growing list of RNA genes within intergenic regions, which seem essential for bacterial virulence. For instance, a recent study combining RNA-seq, transposon mutagenesis, and targeted deletions in Streptococcus pneumoniae identified 89 sRNAs of which a large proportion play important roles in the progression of the infection as well as in tissue tropism (Mann et al. 2012). Overall, the study of regulatory RNAs in bacteria has become a fastgrowing field, which is reflected by the many reviews of their general functions and mechanisms in Gram-negative and Gram-positive bacteria (Storz et al. 2011; Vogel and Luisi 2011).

In this article, we aim to illustrate the fascinating diversity of sRNA action on their cellular targets and the importance of the dynamics in regulation using selected examples from pathogenic bacteria. These examples include independently transcribed (or unique) regulatory RNAs, that either act on other RNA molecules, or target the activity of cellular proteins; and regulatory RNAs that are intricate parts of the messenger RNAs (mRNAs) they regulate. For a more detailed classification of these riboregulators and further work in nonpathogenic organisms, we refer the reader to a number of general reviews of bacterial sRNAs (Gottesman and Storz 2011; Storz et al. 2011) and an excellent book dedicated to the subject (Marchfelder and Hess 2011).

\section{CIS-REGULATORY REGIONS OF MRNAS}

Genome-wide transcriptomic analyses performed in several pathogens, including Helicobacter pylori and Listeria monocytogenes, revealed that the average size of the $5^{\prime}$ untranslated region ( $5^{\prime}$ UTR) of bacterial mRNAs is short, around 20-40 nucleotides long (ToledoArana et al. 2009; Sharma et al. 2010; Wurtzel et al. 2012), which most likely reflects an optimization for ribosome recruitment and efficient translation. However, highly regulated pathways such as growth control, cell division, virulence, stress responses, and metabolism involve many genes with longer $5^{\prime}$ UTRs. These often contain regulatory RNA elements that function as direct sensors of physical (thermosensor) or metabolic cues (Breaker 2009; Narberhaus 2010; Ramesh and Winkler 2010), many of which are well known to alter the expression of virulence factors (Somerville and Proctor 2009).

A widespread cis-acting RNA element in mRNAs is the metabolite-sensing riboswitch (Breaker 2011). These RNA sequences have the ability to bind metabolites with strict specificity, to typically cause a conformational change in the mRNA and alter the expression of the downstream coding sequence at either the levels of transcriptional elongation or translational initiation (Dambach and Winkler 2009). Typically, the riboswitch feedback regulates the associated genes, which are typically involved in the uptake or metabolism of the sensed metabolite (Breaker 2011; Serganov and Nudler 2013). According to sequence and structure conservation (Barrick and Breaker 2007; Yao et al. 2007), riboswitches seem underrepresented in Gram-negative pathogens but may regulate almost $2 \%$ of the genes in Gram-positive bacteria such as Staphylococcus aureus (Caldelari et al. 2011) and L. monocytogenes (Toledo-Arana et al. 2009). Common riboswitches respond to the intracellular concentration of diverse ligands including $S$-adenosylmethionine (SAM), thiamine pyrophosphate (TPP), flavin mononucleotide (FMN), lysine, glycine, guanine, 7-aminomethyl-7-deazaguanine (preQ1), cobalamin, $\mathrm{Mg}^{2+}$, adenosine-triphosphate (ATP), or glucosamine-6-phosphate (GlcN6P). Riboswitches that sense signaling molecules such as the secondary messenger cyclic diguanosine monophosphate (c-di-GMP) have been described in Clostridium difficile and Vibrio cholera (Sudarsan et al. 2008). This dinucleotide is known to regulate a wide variety of functions including the transition from a motile to a biofilm lifestyle, as well as virulence gene expression. As an example of high regulatory complexity, the synthesis of a putative virulence factor of C. difficile is subject to control by an allosteric group I intron, whose self-splicing (and there- 
sRNA Regulation in Bacterial Pathogens

fore, formation of an intact mRNA) is regulated by a c-di-GMP-sensing riboswitch (Lee et al. 2010). In Salmonella typhimurium, a leader mRNA with tandem attenuators senses the intracellular concentration of ATP and of proline in an independent but additive manner (Lee and Groisman 2012a,b). This mRNA encodes $\mathrm{MgtC}$, a protein that is highly produced within macrophages and required for virulence. Most recently, an aminoglycoside-binding riboswitch that is widely distributed among antibiotic-resistant bacterial pathogens has been discovered. This riboswitch is present in the leader RNA of genes and activates the production of enzymes that confer resistance to aminoglycoside antibiotics when these are present in the environment (Jia et al. 2013).

Riboswitches represent promising targets for novel antibacterial compounds that avoid current mechanisms of resistance (Breaker 2009; Mulhbacher et al. 2010b). First, they are generally absent in the eukaryotic host. Second, they are amenable to structural analysis, which has provided atomic-resolution structures for disparate riboswitch classes (Serganov 2010). Nonmetabolizable agonists were recently designed based on the crystal structure of the purine-sensing riboswitch (Mulhbacher et al. 2010a); a pyrimidine derivative compound, $\mathrm{PC} 1$, binds the guanine riboswitch and constitutively switches off the essential guaA gene-encoding GMP synthase. PC1 shows bactericidal activity against $S$. aureus and reduces infection in mice. Importantly, this potential drug has a narrow spectrum activity as it targets exclusively bacteria containing the purine riboswitch, which should reduce selective pressure for resistance in nontargeted bacteria; indeed, no resistant bacteria arose during successive PC1 treatments (Mulhbacher et al. 2010a). Other studies revealed the bacterial toxicity of lysine and thiamine pyrophosphate analogs, which is a result of binding to their respective riboswitches ( $\mathrm{Su}$ darsan et al. 2005; Blount et al. 2006). Moreover, a natural analog of flavin, roseoflavin, is able to recognize the FMN riboswitch (Lee et al. 2009). Roseoflavin is synthesized by Streptomyces davawensis, its only known producer, which itself is resistant to this natural antibiotic thanks to a highly specialized FMN riboswitch that discriminates FMN from roseoflavin (Pedrolli et al. 2012). Roseoflavin affects growth and infectivity of L. monocytogenes through the constitutive repression of a riboflavin transporter, which is controlled by an FMN-sensing riboswitch; in parallel, roseoflavin stimulates virulence gene expression independently of the FMN-sensing riboswitch (Mansjö and Johansson 2011).

Another major class of cis-acting regulatory RNA elements in mRNAs responds to temperature. These RNA thermometers are usually characterized by irregular stem-loop structures (ROSE, FourU motifs) that sequester the ShineDalgarno (SD) region of the associated mRNA (Klinkert and Narberhaus 2009; Kortmann and Narberhaus 2012). At low temperature (below $30^{\circ} \mathrm{C}$ ), these hairpins are typically stable and, hence, the ribosome binding site (RBS) is not accessible for translation. Increasing temperature melts the stem-loop structure to promote translation. At least two major transcriptional activators of virulence genes, LcrF in Yersinia pestis (Hoe and Goguen 1993; Bohme et al. 2012) and PrfA in L. monocytogenes (Johansson et al. 2002), are known to be regulated by thermosensors. LcrF synthesis is regulated by two hierarchical thermosensitive regulators in Yersinia pseudotuberculosis. At moderate temperatures, the $l c r F$ gene is transcriptionally repressed by the thermosensitive modulator protein YmoA, whereas a FourU thermosensor in the $5^{\prime}$ UTR represses mRNA translation. At the host temperature, the SD is liberated for translation initiation (Bohme et al. 2012). Of note, mutations that both stabilize and destabilize the RNA thermometer attenuate the virulence of Y. pseudotuberculosis. Therefore, RNA thermosensors critically contribute to adjusting the concentration of transcriptional activators to promote optimal infection programs.

Last but not least, intracellular $\mathrm{pH}$ has been identified as a regulatory cue for cis-regulation within bacterial mRNAs. In Salmonella, the alx leader of the mRNA of a putative transporter acts as a $\mathrm{pH}$-responsive element. At high $\mathrm{pH}$, the progression of RNA polymerase is affected allowing the refolding of the mRNA to promote its translation (Nechooshtan et al. 2009). 
I. Caldelari et al.

\section{GENERAL PROPERTIES OF REGULATORY RNAs AND THEIR ASSOCIATED PROTEIN MACHINERY}

A staggering number of sRNAs that are bona fide regulators of gene expression have been identified in bacterial pathogens (Felden et al. 2011; Gottesman and Storz 2011; Storz et al. 2011). One group includes sRNAs, which modulate the activities of proteins (Marzi and Romby 2012; Romeo et al. 2012). As outlined further below, these sRNAs possess specific sequence or structural elements that mimic the natural substrates of regulatory proteins, and indirectly impact gene regulation at a global level. The second and the largest group of sRNAs so far act by base-pairing with cellular RNAs, primarily mRNAs. These sRNAs are classified based on genomic localization relative to their mRNA targets. In the first case, the antisense (asRNA) and its target RNA are transcribed in an overlapping fashion from the opposite strands of a DNA region, which usually entails considerable base complementarity. Short and long cis-encoded asRNAs regulate a variety of functions such as virulence, toxins, motility, and biofilm formation (Toledo-Arana et al. 2009; Beaume et al. 2010; Sharma et al. 2010; Lasa et al. 2011; Lioliou et al. 2012; Wurtzel et al. 2012). In the second case, the sRNA is encoded distant to its target(s), and typically shows only partial complementarity, which can be as short as half a dozen nucleotides. These sRNAs tend to regulate multiple rather than single target mRNAs and act in concert with transcriptional regulatory proteins or two-component systems to respond to environmental changes, envelope stress (Gogol et al. 2011), alter nutrient conditions (Beisel and Storz 2011), control quorum sensing (Sonnleitner et al. 2009; Felden et al. 2011; Rutherford et al. 2011), or express virulence genes (Chao and Vogel 2010; Sonnleitner and Haas 2011; Mellin and Cossart 2012).

It has emerged that most of the trans-acting sRNAs in Gram-negative bacteria functionally require and interact with the RNA chaperone protein Hfq (Vogel and Luisi 2011). Coimmunoprecipitation of cellular RNAs with Hfq followed by RNA-seq and other approaches have provided a genome-wide picture of the abundance of sRNAs in the model pathogen S. typhimurium, hinting at a large posttranscriptional network wherein 100-200 sRNAs together with Hfq may control $>25 \%$ of all mRNAs (Padalon-Brauch et al. 2008; Sittka et al. 2008, 2009; Ansong et al. 2009; Chao et al. 2012; Kröger et al. 2012). Many of these mRNAs encode virulence factors, or proteins involved in biofilm formation and motility (Fig. 1). Hfq is also important for the fitness and virulence of many other Gram-negative bacteria and an increasing number of Gram-positive pathogens (Chao and Vogel 2010). There has been considerable progress in understanding how Hfq facilitates sRNA-dependent regulation (i.e., by protecting the sRNAs against degradation, helping them anneal to their mRNA targets, modifying mRNA structure for better accessibility, and recruiting important nucleases such as RNase E) (Vogel and Luisi 2011). The situation is less straightforward in Gram-positive bacteria, in which several important pathogens including Streptococci lack a recognizable $h f q$ gene, whereas others encode Hfq but express it only in a subset of strains within the same species (Romby and Charpentier 2010). In L. monocytogenes, however, $\mathrm{Hfq}$ is required in at least one case of sRNA-mediated mRNA regulation (Nielsen et al. 2011). The various levels of dispensability or requirement of Hfq in several pathogens may result from specific features of $\mathrm{Hfq}$ or sRNAs and their RNA duplexes that still need to be characterized (Jousselin et al. 2009; Horstmann et al. 2012; Romilly et al. 2012).

There is currently very limited information on other RNA-binding proteins that might be involved in sRNA regulation, but new RNAbinding proteins keep emerging through serendipitous findings. For example in S. aureus, the pleiotropic transcriptional regulatory protein SarA was unexpectedly identified as an RNA-binding protein, which altered mRNA turnover (Roberts et al. 2006; Morrison et al. 2012). Whether SarA affects mRNA degradation through sRNAs is still an open question. Moreover, several ribonucleases have been implicated in $S$. aureus virulence (reviewed in Romilly et al. 2012). Among these enzymes, RNase 
sRNA Regulation in Bacterial Pathogens

A

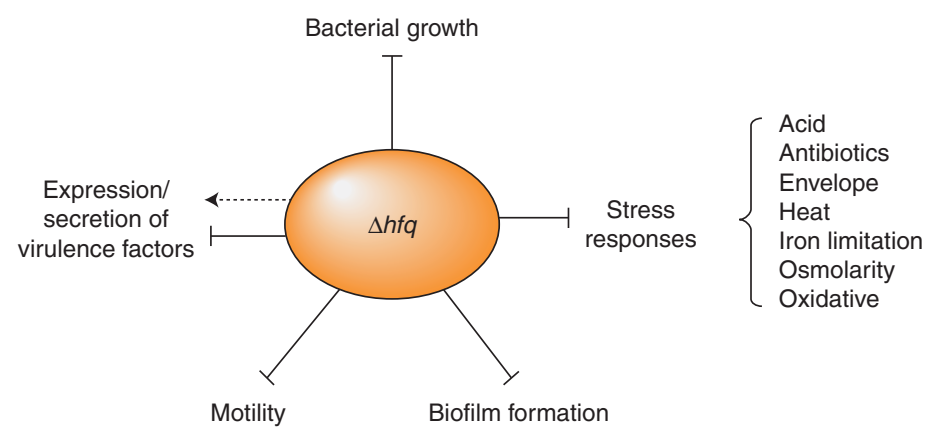

B

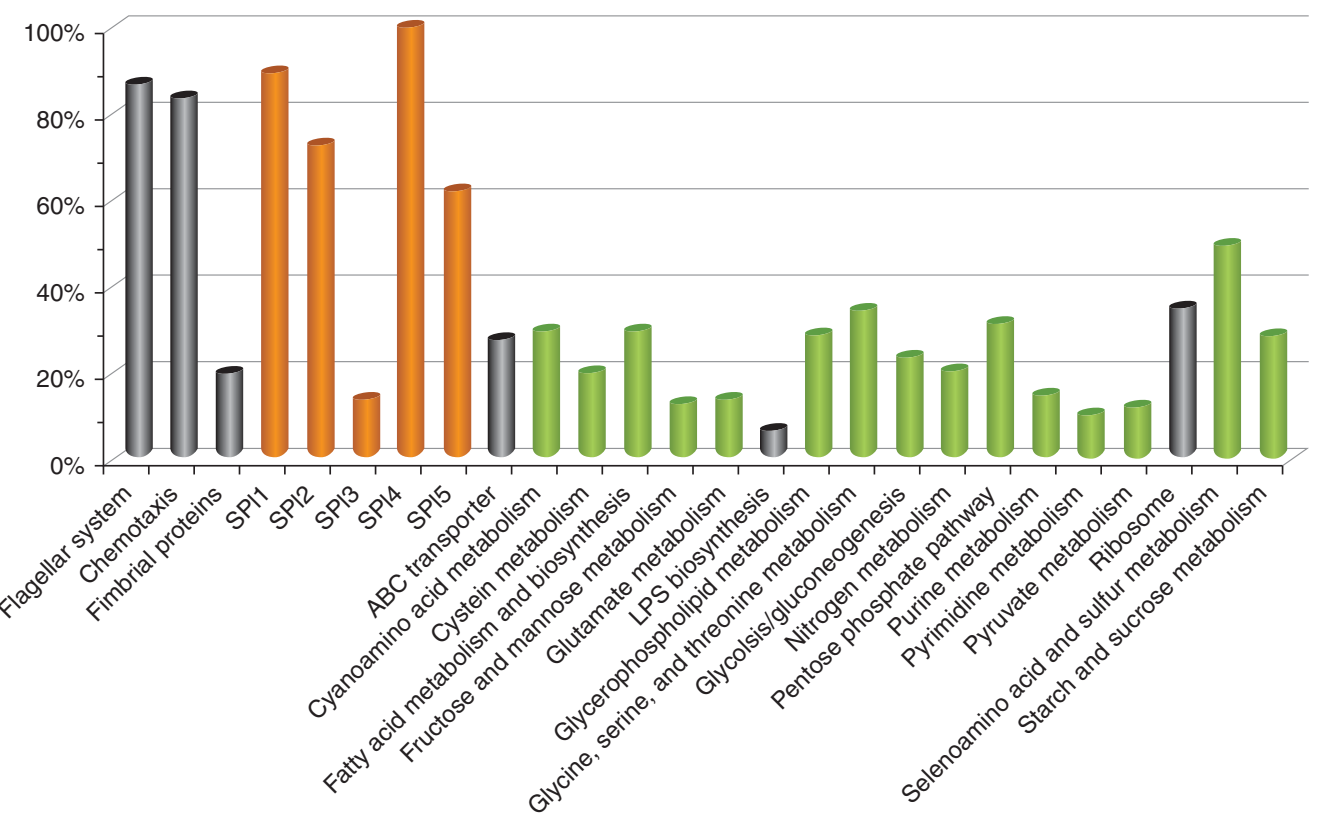

Figure 1. Prominent functions of Hfq in bacterial pathogens. (A) Summary of Hfq protein functions as inferred from the phenotypes of $h f q$ mutants in Gram-negative bacteria (reviewed in Chao and Vogel 2010). In most bacteria examined, inactivation of the $h f q$ gene causes a growth defect, a decrease in motility and biofilm formation, and an inability to cope with environmental stresses. Expression and/or secretion of the type III secretion system can be affected in either a negative or positive manner. (B) Gene ontology analysis of disregulated genes in a Salmonella $h f q$ mutant strain (Sittka et al. 2008). Bars show the percentage of Hfq-dependent genes in each pathway. Orange bars denote the five major virulence regions of S. typhimurium; green bars denote metabolic functions.

III has been clearly identified as a major partner in antisense regulation (Lasa et al. 2011; Lioliou et al. 2012). These latter global analyses using RNA deep sequencing have produced compelling evidence that RNase III processes overlapping 5' UTRs of divergently transcribed genes, and facilitates RNA quality control of pervasive transcription. In Sinorhizobium meliloti, the conserved and ubiquitous metalloprotein SMc01113, ortholog to E. coli YbeY, affects the accumulation of sRNAs and their mRNA targets in a way similar to Hfq (Pandey et al. 2011). This protein, which is conserved in many pathogenic bacteria, shares structural similarities with the MID domain of eukaryotic AGO proteins. These preliminary analyses suggest that bacteria 
I. Caldelari et al.

may use a protein similar to a core component of the corresponding eukaryotic RNA machinery to achieve sRNA-mediated regulation. A recent work shows that E. coli YbeY is a single strand-specific endoribonuclease, which plays key roles in $70 \mathrm{~S}$ ribosome quality control and $16 \mathrm{~S}$ rRNA maturation (Jacob et al. 2013). More generally, we expect a surge in studies in the future that use genetic screens and/or purification of ribonucleoprotein particles followed by high-throughput RNA sequencing to identify the protein cofactors involved in regulating the activity of sRNAs in pathogens.

\section{NOVEL REGULATORY MECHANISMS OF TRANS-ACTING SRNAS}

Pathogenic bacteria do not necessarily use different strategies to regulate gene expression by sRNAs compared to nonpathogenic species. Nonetheless, new mechanisms have been revealed through studies of pathogens. For example, the prototypical mechanism of trans-acting sRNAs is to sequester the RBS of target mRNAs by base-pairing to the SD sequence or start codon. However, recent work in Salmonella discovered alternative repression mechanisms by MicC sRNA and RNase E in the coding sequence of ompD porin mRNA (Pfeiffer et al. 2009; Bandyra et al. 2012) or by Rho-dependent transcription termination within the chiP porin gene by ChiX sRNA (Bossi et al. 2012). Note that work on ChiX also revealed an indirect positive regulation wherein this sRNA is trapped by a pseudotarget mRNA, causing a derepression of its actual target (Figueroa-Bossi et al. 2009).

The prototypical mechanism of target activation was originally discovered in a pathogen (i.e., where RNAIII of $S$. aureus induces hemolysin $\alpha$ synthesis by resolving an inhibitory secondary structure around the RBS of this mRNA through competitive binding) (Fig. 2A). However, various other modes of positive regulation have also been recently discovered in pathogens. For example, the VR-RNA of Clostridium perfringens interacts with the $5^{\prime}$ part of a hairpin structure that sequesters the SD sequence of collagenase mRNA, promoting a specific cleavage and stabilization of this virulence-factor-encoding transcript (Obana et al. 2010). In the human pathogen group A Streptococcus (GAS), the FasX sRNA activates the synthesis of the secreted virulence-factor streptokinase SKA, which aids the dissemination of the pathogen by converting the host plasminogen into the fibrin-degrading protease plasmin (RamirezPena et al. 2010). FasX binds to the ska mRNA within its $5^{\prime}$ end at a UCCC sequence motif, 30 nucleotides upstream of the RBS. This interaction enhances both the stability of the transcript and protein synthesis. Of note, Gram-positive bacteria possess $5^{\prime}$-to- $3^{\prime}$ exoribonuclease activity (Condon and Bechhofer 2011), which might explain why blocking the $5^{\prime}$ end of ska mRNA

Figure 2. Dual functions of peptide-coding small RNAs. (A) Quorum sensing and RNAIII-controlled gene expression. S. aureus produces an autoinducing peptide that is sensed by a histidine kinase (AgrC). Sensing of the autoinducing peptide by AgrC leads to phosphorylation of the response regulator AgrA, which, in turn, is a transcriptional activator of the bifunctional RNAIII. RNAIII encodes the hld gene (coding for $\delta$-hemolysin), and posttranscriptionally regulates several target mRNAs. Whereas spa, coa, rot, SA1000, and SA2353 mRNAs are repressed by RNAIII (Boisset et al. 2007), the hla mRNA is activated by this bifunctional RNA (Morfeldt et al. 1995). Red and blue arrows denote sRNA-mediated posttranscriptional activation and repression, respectively. (B) Glucose-phosphate stress and SgrS modulates virulence gene expression. The accumulation of glucose phosphate in the cytoplasm is sensed by the transcription factor SgrR, which, in turn, activates transcription of the SgrS RNA. The $5^{\prime}$ region of SgrS encodes a small peptide SgrT (43 amino acids), whereas the $3^{\prime}$ region contains a seed-pairing domain that targets several mRNAs with the help of the RNA chaperone Hfq. In addition to targeting the conserved sugar transporters $p t s G$ and manXYZ, SgrS also represses the mRNA of the T3SS secreted virulence effector SopD in Salmonella (Papenfort et al. 2012). (C) PhrS sRNA in Pseudomonas. Binding of the PhrS sRNA induces the translation of the quorum-sensing regulator PqsR translational activation of an upstream ORF (uof), which is coupled to PqsR (Sonnleitner et al. 2011). Expression of PhrS is induced by ANR, an oxygen-responsive regulator, at high-cell density populations when oxygen becomes limiting. 
sRNA Regulation in Bacterial Pathogens
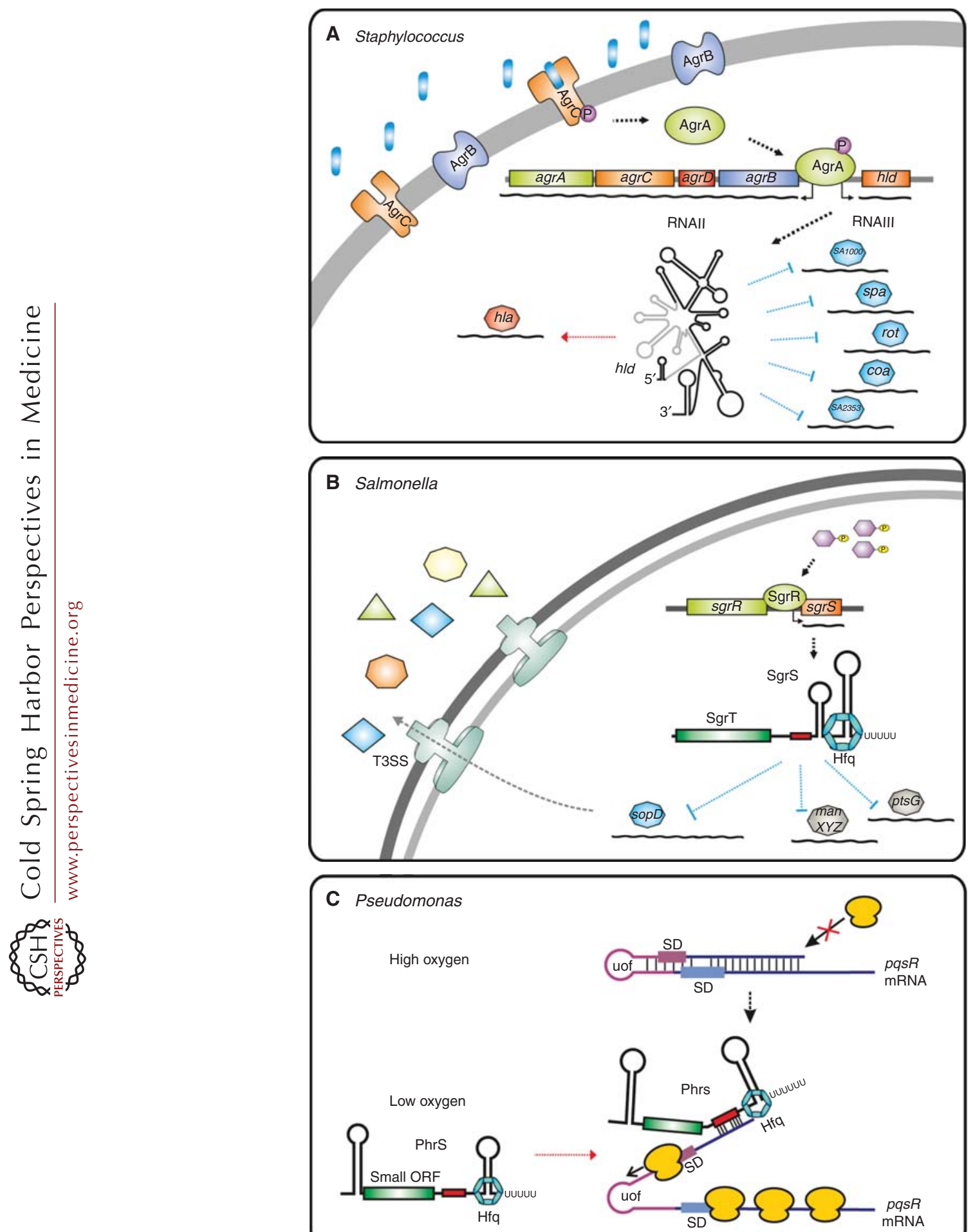

Figure 2. (See legend on facing page.) 
I. Caldelari et al.

increases mRNA stability. Finally, work on the PhrS RNA in Pseudomonas aeruginosa (Fig. 2C) has revealed a mode of indirect target activation through promoting ribosome binding to a small upstream open reading frame (uof) whose translation is coupled to $p q s R$ (Sonnleitner et al. 2011).

In the following section, several representative examples will illustrate the variety of sRNAdependent mechanisms and functions that contribute to pathogenesis.

\section{SMALL RNAs ESTABLISH A GRADIENT OF RESPONSES IN QUORUM SENSING}

In Vibrio species, the control of quorum sensing (QS) by 4-5 paralogous sRNAs (Qrr1-5) is a well-studied process ( $\mathrm{Ng}$ and Bassler 2009). At low cell density, the transcriptional regulator LuxO is continuously phosphorylated and in conjunction with RNA polymerase-bound $\sigma^{54}$ drives the transcription of the Qrr sRNAs that base-pair to and down-regulate the hapR mRNA (Fig. 3) (Lenz et al. 2005; Bardill et al. 2011). Active HapR inhibits the expression of virulence genes and type III secretion, whereas it induces the production of proteases and several other genes. In contrast, at high cell density, LuxO phosphorylation is inhibited and HapR is expressed (Fig. 3). Interestingly, Qrr4 also represses the luxO mRNA, which effectively creates a posttranscriptional feedback loop that facilitates precise gene regulation during the transition from the exponential to the stationary phase of growth (Tu et al. 2010). The Qrr sRNAs also directly activate the expression of AphA (Fig. 3), which is a transcriptional repressor of the hapR gene and the dominant QS regulator at low cell density conditions (Rutherford et al. 2011; Shao and Bassler 2012). The regulatory architecture linking the Qrr sRNAs, HapR, and AphA allows maximal AphA levels at low cell

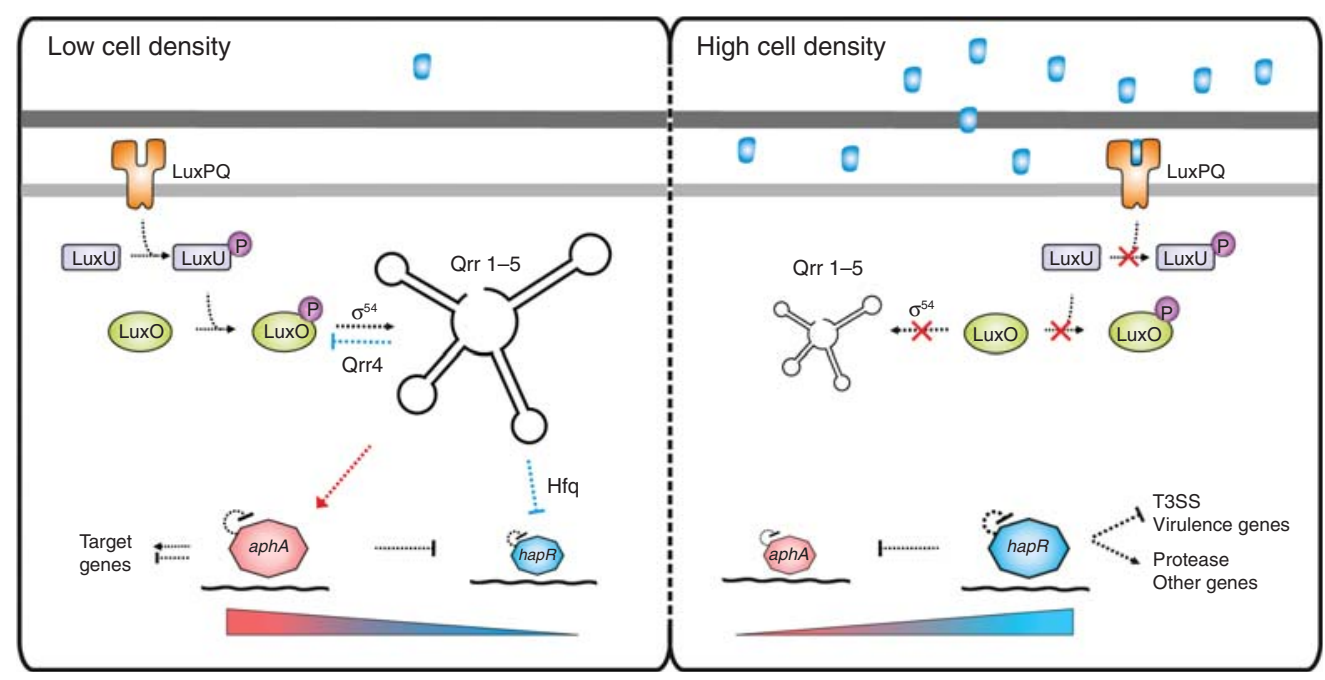

Figure 3. Several sRNAs regulate quorum sensing in Vibrio cholerae. At low cell density, the histidine kinasereceptor LuxPQ phosphorylates LuxU, which, in turn, phosphorylates LuxO (LuxO-P). LuxO-P, together with the RNAP- $\sigma^{54}$ holoenzyme, activates the transcription of 5 sRNAs, Qrr1-5 (Rutherford et al. 2011). These sRNAs together with Hfq repress the translation of hapR mRNA and activate the translation of ahpA mRNA through an anti-antisense mechanism. Qrr4 also represses the translation of luxO mRNA, thus creating a negative-feedback regulation. At high cell density and high concentrations of extracellular autoinducer-2, the LuxPQ receptor acts as a phosphatase and dephosphorylates LuxO. In consequence, the synthesis of Qrr sRNAs is arrested and the synthesis of HapR is derepressed, and a gradient of higher concentrations of HapR (in blue) over AphA (in pink) is established to provide a large range of responses. In addition, AphA and HapR autoregulate their own synthesis at the transcriptional level. Red and blue arrows denote sRNA-mediated posttranscriptional activation and repression, respectively. 
sRNA Regulation in Bacterial Pathogens

density, whereas HapR production is strongest at high cell density. Hence, the Qrr sRNAs act as the switch determining which transcription factor is expressed, and cause reciprocal gradients of AphA and HapR concentrations to establish the gene expression patterns at low and high cell density (Fig. 3) (Rutherford et al. 2011). Mechanistically, two conserved regions in the Qrr4 of $V$. cholerae were identified to base-pair with mRNA targets of this sRNA, aphA and $h a p R$, and are used to discriminate between them (Shao and Bassler 2012). In this context, sRNAs are at the heart of a dynamic system to precisely control the expression of quorumsensing-controlled genes by balancing the levels of cell density master regulators during growth.

\section{SMALL RNAs ARE REGULATORS OF VIRULENCE GENES AND SIGNALING PATHWAYS}

The two most recent additions to the list of $\mathrm{Vi}$ brio sRNA regulators affecting pathogenicity are TarA and TarB sRNAs, both of which are controlled by the master virulence regulator ToxT. TarA negatively regulates the major Vibrio glucose transporter ptsG (Richard et al. 2010), whereas TarB down-regulates the secreted colonization factor TcpF (Bradley et al. 2011). TarB also decreases the expression of another transcription regulator, $\mathrm{VspR}$, belonging to the $\mathrm{Vi}$ brio seventh pandemic island-1 (VSP-1) (Davies et al. 2012). VspR directly represses a gene that encodes a new family of dinucleotide cyclases. Cyclic nucleotides play a role in biofilm formation, flagellum biosynthesis, DNA integrity, and cell membrane stress. In $V$. cholerae, the signal molecule seems to be predominantly cAMPGMP, whose accumulation represses chemotaxis, and as an indirect effect enhances intestinal colonization by the bacterium (Davies et al. 2012). This study shows for the first time a link between sRNA-dependent regulation and intracellular signal molecules as cyclic dinucleotides, which modulate various cellular activities including pathogenesis and the transition between sessility and motility. Another sRNA, VrrA, of $V$. cholerae modulates the infection of the host intestinal tract and contributes to bacterial fit- ness in response to stressful environments. This sRNA represses the translation of ompA mRNA and causes a significant reduction of TcpA, a toxin coregulated pilus (Song et al. 2008).

In Yersinia pestis, the formation of biofilms is dependent on exopolysaccharide synthesis, which is controlled by the intracellular yields of c-di-GMP. Hfq was recently shown to activate the expression of the c-di-GMP phosphodiesterase $\mathrm{HmsP}$ at the transcriptional level while it also induces rapid degradation of $h m s T$ mRNA encoding the diguanylate cyclase via the $5^{\prime}$ UTR (Bellows et al. 2012). Whether these regulatory events are mediated through the binding of sRNAs is unknown. However, dysregulation of c-di-GMP turnover and severe attenuation of pathogenesis in the $h f q$ mutant suggest that sRNAs are involved in the c-di-GMP-mediated response to environmental conditions regulating virulence.

\section{DUAL-FUNCTION RNAs ENCODING BOTH A PROTEIN AND A RIBOREGULATOR}

The prime example of a bifunctional sRNA is the well-characterized staphylococcal RNAIII, which is the main intracellular effector of QS (Novick 2003). The noncoding parts of RNAIII control gene expression at the posttranscriptional level via an antisense mechanism (Fig. 2A). The $5^{\prime}$ UTR of RNAIII binds to the leader region of hla mRNA to facilitate ribosome recruitment, whereas the large $3^{\prime}$ UTR primarily acts as a repressor domain. The $3^{\prime}$ UTR contains three redundant hairpin structures with conserved C-rich sequences located in their apical loops. This motif is often used to bind G-rich sequences in mRNAs located primarily in the RBS (Huntzinger et al. 2005; Boisset et al. 2007; Chevalier et al. 2010). Although the topologies of the RNAIII-mRNA duplexes are different, they all efficiently prevent ribosome binding and recruit the double-strand-specific RNase III, which initiates the rapid degradation of the repressed mRNAs. The repressed mRNAs encode adhesin factors (protein A, coagulase, SA1000) and the transcriptional repressor of toxins, Rot (Geisinger et al. 2006; Boisset et al. 2007). Thus, the temporal regulation of vir- 
I. Caldelari et al.

ulence factors favors the transition of the bacterial population from a defensive mode (colonization) toward an offensive mode (dissemination). Besides the regulatory functions, RNAIII contains the hemolysin $\delta$ ORF ( $h l d$ ), which produces a phenol-soluble modulin. Both hemoly$\sin \delta$ peptide and the riboregulatory part of RNAIII play roles in virulence (Novick and Geisinger 2008). Surprisingly, the synthesis of hemolysin $\delta$ was found delayed by $1 \mathrm{~h}$ after the transcription of RNAIII and this delay was abolished when the repressor domain located at the $3^{\prime}$ end of RNAIII was deleted (Balaban and Novick 1995). Whether the regulatory activities of RNAIII might influence hld translation awaits further experimental works.

SgrS is a well-conserved bifunctional RNA in enteric bacteria and is transcribed in response to glucose-phosphate stress to prevent the inhibition of cell growth. It acts by inhibiting translation followed by degradation of mRNAs encoding sugar transporters (Fig. 2B). In the particular case of the manXYZ operon in $E$. coli, SgrS binds to two specific sites in the manX coding region and in the manX-manY intergenic region. Pairing at both sites is required for efficient mRNA degradation, but pairing at one site only is sufficient to inhibit translation of the respective genes (Rice et al. 2012). SgrS also contains a small ORF, SgrT, which prevents glucose uptake by the transporters (Wadler and Vanderpool 2007). In Salmonella, the SgrS sRNA uses its conserved seed-pairing domain in its $3^{\prime}$ end to repress both the major sugar uptake proteins (as in E. coli) and the Salmonella-specific secreted effector protein SopD (Fig. 2B). Strikingly, the almost identical SopD2 protein is not regulated by SgrS, owing to a single hydrogen bond difference in the duplexes formed by SgrS with the sopD or sopD2 mRNAs (Papenfort et al. 2012). SgrS is up-regulated under different stress conditions, and its genomic deletion attenuates Salmonella virulence in mice (Santiviago et al. 2009).

A third example of a bifunctional RNA from a pathogen is PhrS of $P$. aeruginosa (Fig. 2C). $\mathrm{PhrS}$ is an activator of one of the key quorumsensing regulators, PqsR, in this organism, and achieves activation by an interesting mecha- nism. It activates by base-pairing a short upstream ORF to which the $p q s R$ gene is translationally coupled, and so increases protein synthesis of PqsR, too. The PhrS RNA also encodes a conserved protein whose expression has been confirmed but whose cellular function remains to be elucidated (Sonnleitner et al. 2011).

\section{TRANS-ACTING sRNAs MADE FROM THE UTRs OF mRNAs}

Work in several pathogenic bacteria has shown that $5^{\prime}$ UTRs and $3^{\prime}$ UTRs of mRNAs can accumulate as stable RNA species, suggesting that they might function as riboregulators in trans (e.g., Toledo-Arana et al. 2009; Beaume et al. 2010; Sharma et al. 2010). This concept was originally termed "parallel transcriptional output" following observations of short distinct RNA species that accumulated from UTRs and riboswitch regions in nonpathogenic E. coli (Vogel et al. 2003).

Recent work in L. monocytogenes has produced proof of this concept, demonstrating that cis-acting riboswitches located in the $5^{\prime}$ UTR of mRNAs can also regulate gene expression in trans. The L. monocytogenes genome encodes for seven putative SAM riboswitches, named SAM riboswitch element (SreA-G). In low-nutrient conditions, SreA is transcribed together with its downstream genes. In contrast, under rich medium conditions, SreA is produced as an sRNA owing to premature transcriptional arrest, and binds to the prfA mRNA 80 nucleotides upstream of the SD sequence to repress translation (Fig. 4A). Because the prfA mRNA encodes a transcriptional activator of virulence factors, the data establishes a link between metabolism and pathogenesis. The regulation of PrfA synthesis is unique because the prfA mRNA also contains a thermosensor allowing the coordinated expression of virulence factors at the permissive temperature of the host. Its $5^{\prime}$ UTR folds into a stable hairpin structure sequestering the $\mathrm{SD}$ at $30^{\circ} \mathrm{C}$ (Johansson et al. 2002). At $37^{\circ} \mathrm{C}$, this structure is destabilized allowing PrfA expression and consequently the synthesis of virulence factors. The trans-acting regulatory effect of SreA only occurs at $37^{\circ} \mathrm{C}$ 


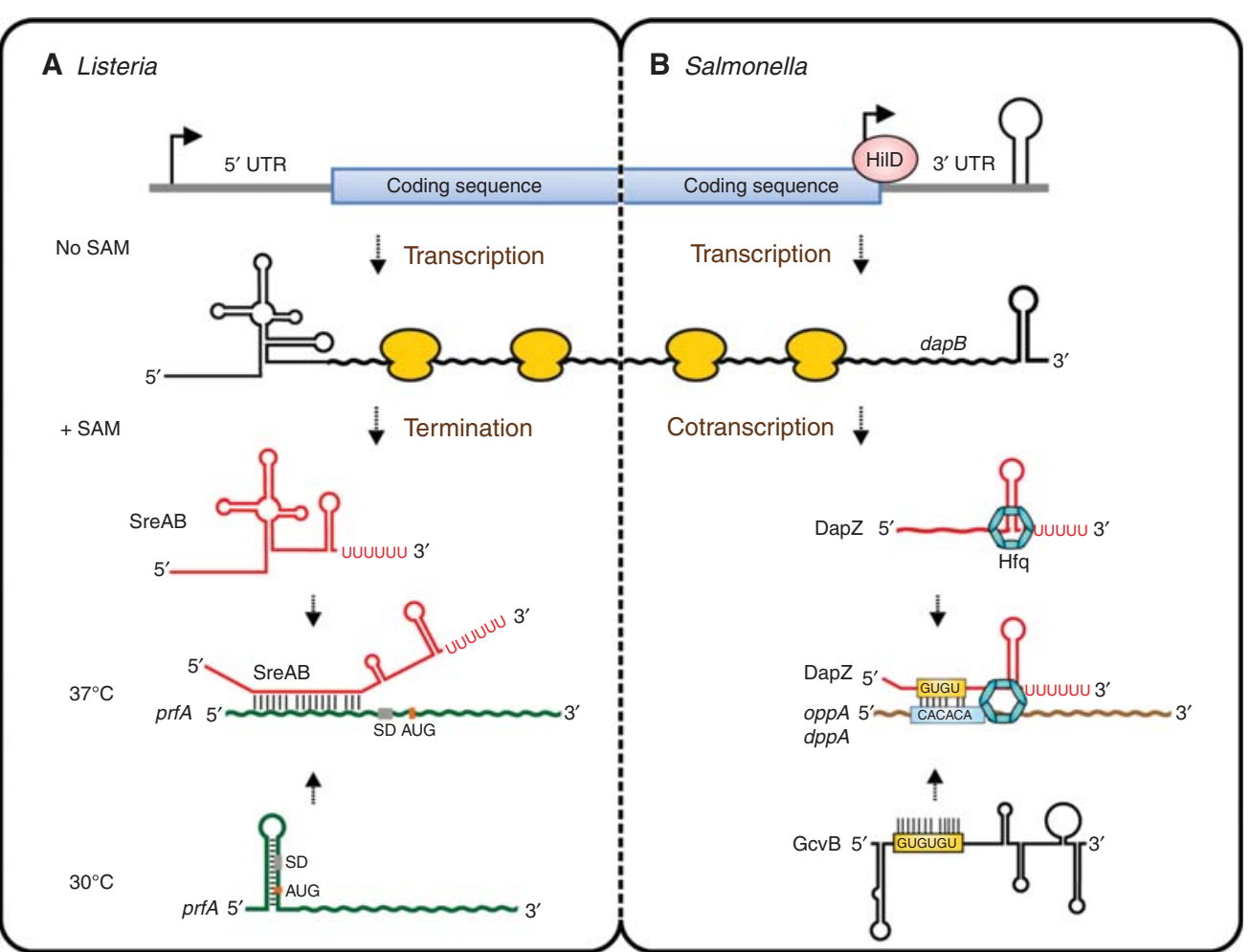

Figure 4. UTR-derived trans-acting small RNAs. (A) $5^{\prime}$ UTR-derived sRNA in L. monocytogenes. During the exponential phase of growth (i.e., under rich nutrient conditions), $S$-adenosylmethionine (SAM) binds to SreA, the terminator structure (in red) is formed, and transcription is prematurely halted (Loh et al. 2009). At $37^{\circ} \mathrm{C}$, the prfA thermosensor (in green) melts to expose the SD for PrfA synthesis and consequently the virulence factors are produced. Under these conditions, the SreA-terminated transcript represses prfA mRNA translation by binding to the $5^{\prime}$ UTR 80 bp upstream of the SD and turning off its expression by an unknown mechanism. (B) $3^{\prime}$ UTR-derived sRNA in S. typhimurium. The synthesis of DapZ (in red) is induced by HilD, the master regulator of Salmonella invasion genes. DapZ carries a short unpaired G/U-rich region that initiates binding to the conserved C/A-rich regions in $d p p A$ and $o p p A$ mRNAs, which encode the major $A B C$ transporters (Chao et al. 2012). The same target sites are recognized by a similar G/U-rich seed region of GcvB sRNA, the master sRNA regulator of amino acid transporters.

when the thermosensor is melted rendering the complementary sequences to SreA available for binding. This novel mechanism of riboswitch functioning in trans suggests that revisiting known cis-acting RNAs in different growth conditions may provide new insights into RNA regulation (Loh et al. 2009). Indeed, other riboswitches such as the ones sensing riboflavin or thiamine have also been known to produce sRNAs (Vogel et al. 2003).

There is now evidence that $3^{\prime}$ UTRs also produce RNA species that act in trans. A recent study analyzed Hfq-associated RNA species from multiple stages of growth in S. typhymurium, and revealed a large number of new sRNAs that originated from mRNA loci (Chao et al. 2012). The Hfq association strongly suggests that these new sRNAs are functional, rather than being passive degradation products. One of them, called DapZ, coincides with the $3^{\prime}$ region of the biosynthetic gene $\operatorname{dap} B$. It is transcribed from a promoter just upstream of the $\operatorname{dap} B$ stop codon, but terminates at the same stem-loop structure as the longer, protein-coding dapB mRNA. Importantly, in Salmonella, this gene-internal dapZ promoter evolved to be 
I. Caldelari et al.

activated by the regulator of invasion genes, HilD, rendering DapZ sRNA production part of a Salmonella-specific virulence program (Fig. 4B). DapZ uses a short G/U-rich seed sequence to repress the $d p p A$ and $o p p A$ mRNAs encoding major $\mathrm{ABC}$ transporters (Chao et al. 2012). Thus, this Hfq-dependent sRNA from an mRNA 3 ' UTR is functionally homologous to GcvB, an sRNA that regulates many amino acid transporters (Sharma et al. 2011). There are many other Salmonella mRNAs with potential double output, producing both a protein and an Hfq-dependent sRNA from their $3^{\prime}$ UTRs under virulence conditions (Chao et al. 2012).

\section{THE FUNCTIONAL IMPACT OF LONG AND SHORT FULLY COMPLEMENTARY aSRNAS}

Transcriptomic analyses in several pathogenic bacteria have revealed a high occurrence of antisense transcription throughout their genomes. Recent studies have reported different roles of such antisense transcripts (Fig. 5). An unusually long antisense RNA of $1.2 \mathrm{~kb}$ (lasRNA), AmgR, was identified in Salmonella (Lee and Groisman 2010). AmgR is transcribed from a promoter located in the $m g t C-m g t B$ intergenic region of the polycistronic $m g t C B R$ mRNA, which encodes an inner membrane $\mathrm{Mg}^{2+}$ transporter, and a 30-amino-acid-long peptide involved in the proteolysis of $\mathrm{MgtC}$, respectively (Fig. 5A). The MgtC protein is necessary for survival within macrophages, virulence in mice, and growth at low $\mathrm{Mg}^{2+}$ concentrations (Lee and Groisman 2010). Expression of AmgR induces rapid degradation of the $m g t C$ and $m g t B$ mRNAs in an RNase-E-dependent manner that does not require Hfq. Intriguingly, the transcription of both $m g t C B R$ and $a m g R$ is activated by the PhoP transcription factor but the promoter of $a m g R$ is weaker. Surprisingly, inactivation of the chromosomal amgR promoter enhances Salmonella virulence most likely owing to enhanced levels of MgtC and MgtB. Thus, AmgR functions as a temporal regulator to alter $\mathrm{MgtC}$ and $\mathrm{MgtB}$ levels after the onset of PhoP-inducing conditions, which is critical for Salmonella virulence.

Another type of lasRNA was identified in pathogenic and nonpathogenic Listeria strains.
They are rather large in size (up to $6.5 \mathrm{~kb}$ ), overlap one ORF, and serve as the $5^{\prime}$ UTR of a neighboring encoded ORF. For one of these lasRNAs, it was experimentally shown that its proximal part negatively regulates the expression of the gene transcribed on the opposite strand and that its distal part acts as a polycistronic mRNA for the downstream operon (Fig. 5B). Interestingly, the expression of one of these dual-functional lasRNAs leads to an activation of a permease and results in a simultaneous silencing of the associated efflux pump. This particular type of genomic locus, encoding an unusually long asRNA that spans divergent genes or operons with related or opposing functions, has been termed an "excludon" (Toledo-Arana et al. 2009; Wurtzel et al. 2012; Sesto et al. 2013). Overlapping transcripts from divergently transcribed genes may also generate a positive regulation. In S. aureus, several divergent mRNAs contain overlapping $5^{\prime}$ UTRs, which are processed by RNase III (Lioliou et al. 2012). This processing generates functional mRNAs but with shorter $5^{\prime}$ UTRs. Whether this processing has a positive effect on translation has yet to be analyzed.

Another study using RNA deep sequencing to analyze short RNA fractions of $S$. aureus has revealed a large collection of 22-nucleotide RNA fragments generated by RNase III digestion of sense/antisense transcripts from all over the chromosome (Lasa et al. 2011). More than $75 \%$ of the mRNAs were subjected to specific RNase III processing as the result of antisense regulation. Deletion of RNase III significantly reduces the amount of short RNA fragments and concomitantly leads to the accumulation of low levels of antisense transcripts. These data are indicative of genome-wide antisense transcription, which is hidden owing to RNase III processing of sense/antisense transcripts. Interestingly, the involvement of RNase III in this novel posttranscriptional process appears to be restricted to Gram-positive bacteria (Lasa et al. 2011).

A particular mechanism of antisense regulation has been recently proposed for the staphylococcal type I toxin-antitoxin SprA1/SprA1AS (Sayed et al. 2011). SprA1 encodes a peptide, 
sRNA Regulation in Bacterial Pathogens

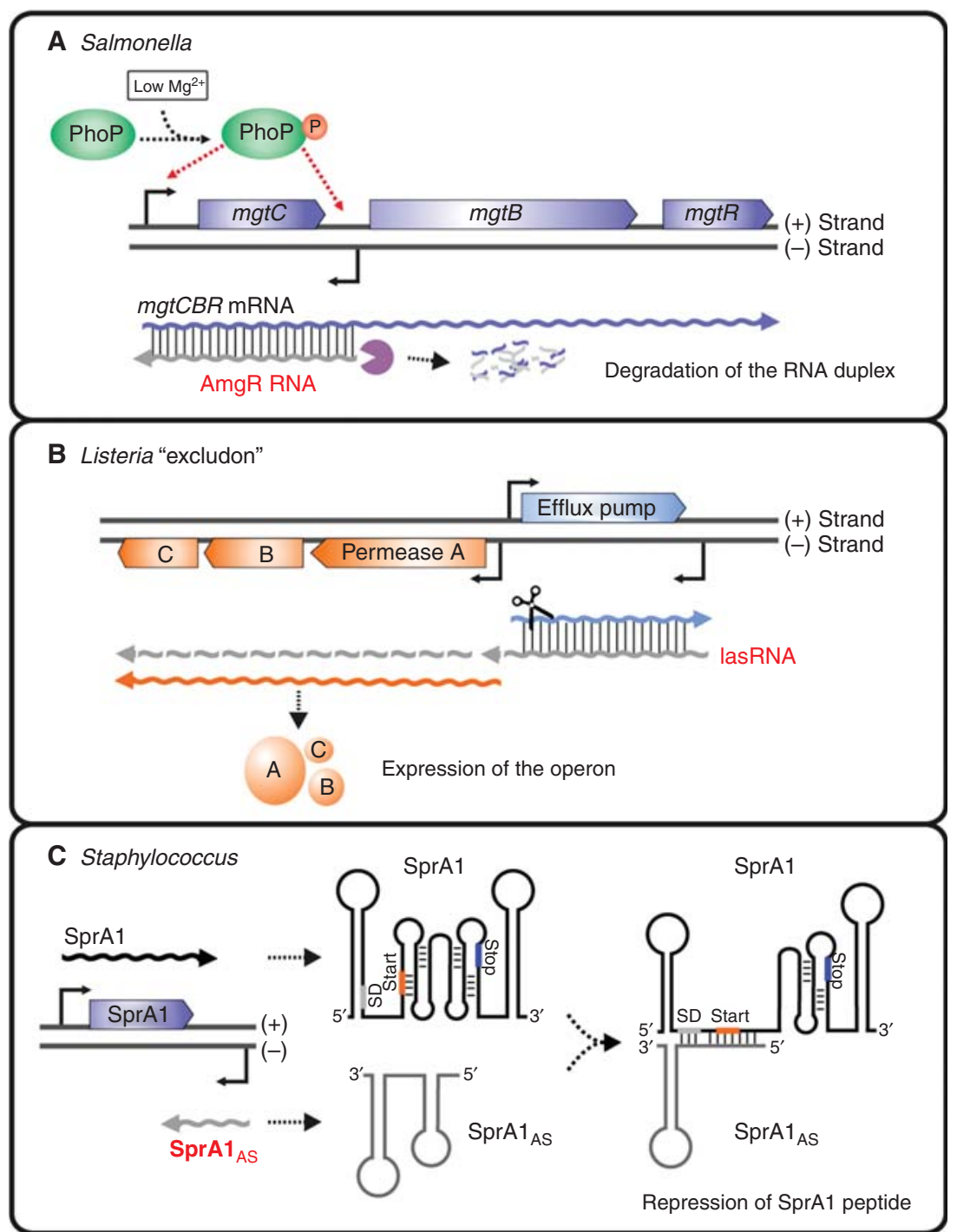

Figure 5. Novel regulations by long and short antisense RNAs. (A) AmgR is a 1.2-kb cis-encoded RNA that is expressed convergently to the $m g t C$ ORF in Salmonella (Lee and Groisman 2010). When $\mathrm{Mg}^{2+}$ concentrations are low, the PhoPQ two-component system activates expression of both the AmgR and $m g t C$ transcripts. The interaction of these two RNAs results in RNase-E-dependent degradation of the RNA duplex. (B) Unusually long antisense RNAs have been predicted upstream of many operons in Listeria (Wurtzel et al. 2012). Expression of these lasRNAs may activate the downstream operons while inhibiting the expression of genes located antisense to them, which usually have opposite functions to the operon. (C) $\operatorname{SprA1}_{\mathrm{AS}}$ is a short, $\sim 60$-nucleotide-long antisense RNA of a toxin-antitoxin (TA) system in S. aureus. It overlaps with the $3^{\prime}$ end of the dual-functional SprA1 sRNA. SprA1 $1_{\mathrm{AS}}$ was shown to use its $5^{\prime}$ end to base-pair with SprA1 sRNA through imperfect pairing, and to repress the translation of the SprA1-encoded small cytolytic peptide (Sayed et al. 2011). 
I. Caldelari et al.

which has lytic activity toward human erythrocytes and displays antimicrobial activity against Gram-positive and Gram-negative bacteria. Surprisingly, structure probing combined with mutational analysis shows that the short SprA1AS binds to the RBS of SprA1 through imperfect pairings to prevent translation of the peptide. Unexpectedly, the interacting region does not involve the $3^{\prime}$ end of SprA1-AS, which is fully complementary to the $3^{\prime}$ end of SprA1. Instead, the active region is located in its $5^{\prime}$ part that is partially complementary to the RBS of SprA1 (Fig. 5C). The fully complementary regions of both RNAs corresponded to stable Rho-independent terminators, which are probably unfavorable to promote the rapid formation of stable intermolecular pairings. Hence, the $5^{\prime}$ unpaired region of SprA1-AS may be more appropriate to promote fast binding with the connecting loop L2 of the pseudoknot of SprA1, a mechanism often used by sRNAs from Gramnegative bacteria (Papenfort et al. 2010).

\section{SMALL RNAs AS DECOYS TO REGULATE THE REGULATORY ACTIVITIES OF PROTEINS}

As mentioned earlier, a limited number of sRNAs modulate the activity of posttranscriptional regulators (Fig. 6). Among them, $\mathrm{Crc}$ and CsrA/RsmA are RNA-binding proteins discovered in Pseudomonas species (Babitzke et al. 2009; Rojo 2010; Romeo et al. 2012). They share functional resemblances, but no amino acids sequence and structure similarities. Both proteins are involved in gene regulation of several processes like secondary metabolism, carbon storage, stress response, and virulence, and repress translation of target mRNAs. For example, Crc binds with high affinity to an unpaired AANAANAA sequence (in which $\mathrm{N}$ is $\mathrm{C}=$ $\mathrm{U}>\mathrm{A}$ ) located upstream of or downstream from the AUG initiation codon of mRNAs to repress their translation (Moreno et al. 2009; Sonnleitner et al. 2009). Furthermore, they are themselves controlled by sRNA-mediated regulation (Fig. 6). Indeed, CsrZ sRNA from $P$. aeruginosa (Sonnleitner et al. 2009) and CsrY and CrsZ in Pseudomonas putida (Moreno et al. 2012) contain several Crc recognition mo- tifs AANAANAA. CsrZ and CsrY act as antagonists and sequester $\mathrm{Crc}$ allowing translation of the target mRNAs (Fig. 6B). Similarly, the activity of RsmA is antagonized by two sRNAs, RsmY and RsmZ, whose expression is exclusively regulated by the GacS/GacA two-component system, the master regulator of virulence in P. aeruginosa (Fig. 6A). The GacA-response regulator transduces external regulatory signals and binds exclusively to two chromosomal loci to activate the expression of RsmYand RsmZ (Brencic et al. 2009). Both RsmY and RsmZ contain multiple GGA motifs to sequester RsmA (Heurlier et al. 2004; Kay et al. 2005). RsmA itself binds to the conserved GGA motifs located in the $5^{\prime}$ UTR of target mRNAs, resulting in translational repression. In summary, RNA mimicry regulates many processes that can directly alter the function of nucleic acid-binding proteins (Marzi and Romby 2012).

Finally, 6S RNA is a (structurally) well-conserved sRNA in all bacteria. It interacts with the housekeeping form of RNA polymerase in complex with $\sigma^{70}$ and inhibits expression from certain promoters when the bacteria shift from the exponential to the stationary phase of growth (Wassarman 2007). The sequestration of $\sigma^{70}$ by $6 \mathrm{~S}$ RNA down-regulates $\sigma^{70}$-dependent transcription thereby facilitating transcription from stationary phase $\sigma$-factor-dependent promoters. The involvement of 6S RNA in pathogenesis was first shown in Legionella pneumophila, which is a Gram-negative opportunistic human pathogen that infects and multiplies in a broad range of phagocytic protozoa and mammalian phagocytes. The 6S RNAwas shown to positively regulate the expression of genes encoding type IVB secretion system effectors, stress response genes, as well as many genes involved in the acquisition of nutrients (Faucher et al. 2010). Deletion of 6S RNA significantly reduces $L$. pneumophila intracellular multiplication in both protist and mammalian host cells.

\section{GENERAL CONCLUSION AND PERSPECTIVES}

The analysis of sRNAs in bacterial pathogens is undergoing a paradigm shift because deep se- 

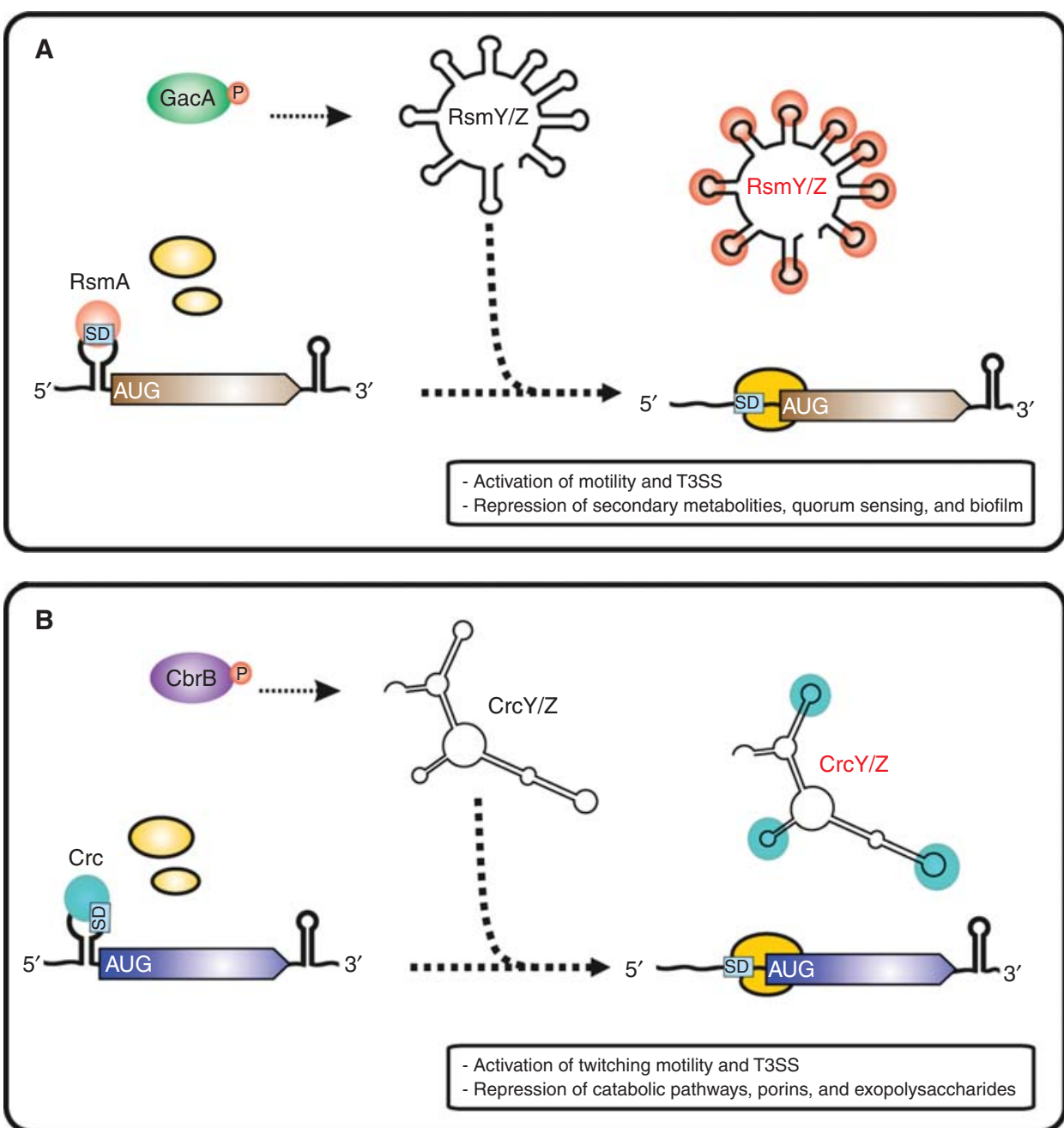

Figure 6. Small RNAs directly regulate protein activity in Pseudomonas. (A) RsmA is an RNA-binding protein that modulates gene expression by antagonizing translational initiation (Lapouge et al. 2008). The RsmY/Z RNAs contain multiple RsmA binding sites and counteract RsmA activity via a titration mechanism in several different plant and human pathogens. Similar small RNAs (e.g., CsrB) target the homologous CsrA protein in enterobacteria (Romeo et al. 2012). (B) Crc is an RNA-binding protein that modulates expression by antagonizing translational initiation (Moreno et al. 2009). CrcY/Z RNAs carry up to six Crc-binding sites and counteract Crc activity via a titration mechanism.

quencing can rapidly discover and report expression profiles of, in principle, all RNAs of an organism. Recently, deep sequencing performed on several major pathogens such as $S$. aureus (Beaume et al. 2010; Bohn et al. 2010; Lasa et al. 2011), H. pylori (Sharma et al. 2010), L. monocytogenes (Oliver et al. 2009; Wurtzel et al. 2012), S. pneumoniae (Mann et al. 2012), or V. cholerae (Mandlik et al. 2011) has revealed hundreds of previously undetected transcripts in both sense and antisense orientations. $\mathrm{Nu}$ merous short transcripts derived from $5^{\prime}$ or $3^{\prime}$ UTRs, or internal regions of mRNAs have been detected, and some of them were recently shown to behave as independent modules (Loh et al. 2009; Chao et al. 2012). Novel mechanisms have been found in representative pathogens of Gram-positive bacteria in which sRNAs bind at 
I. Caldelari et al.

the $5^{\prime}$ end of the target mRNA to protect the mRNAs against degradation, which is a mechanism that has not yet been found in Gram-negative bacteria. It is now time to explore other avenues such as sRNA-mediated modulation of chromosome structure, sRNA-dependent activation of virulence factors, sRNAs that affect the mobility of pathogenicity islands, the expression of host genes, or cell-to-cell communication. Efforts to combine experimental and computational approaches will advance our knowledge of sRNA functions and of their regulons. The importance of the sRNA and mRNA structures, the identification of the initial contacts, the possibility to form multiple binding sites and noncanonical base pairs, the stoichiometry of sRNA-mRNA complexes are criteria that need to be taken into account to improve the search for primary targets.

Most studies have provided a static picture of sRNA-dependent regulation in a population of cells. However, identical genotype and growth environments are insufficient to ensure that individual cells within clonal microbial cultures will show the same phenotype (Gefen and Balaban 2009). This heterogeneity confers the ability of a population to persist in response to external changes and to exploit new niches. Biofilm formation represents such heterogeneity of cells within an isogenic bacterial cell population. A recent study has shown that the major biofilm regulator CsgD in Salmonella is expressed in a bistable manner during the biofilm development (Grantcharova et al. 2010). Interestingly, ArcZ sRNA repressed the translation of the $c s g D$ mRNA and contributed to the transition between sessility and biofilm formation (Papenfort et al. 2009; Monteiro et al. 2012). Whether ArcZ contributes to the bistable expression of CsgD remains to be studied.

Only a few of the known sRNAs have been functionally characterized in vivo (Mann et al. 2012). A novel approach, TRADIS (i.e., transposon directed insertion-site sequencing), has been developed to simultaneously assay every gene of S. typhimurium for essentiality (Langridge et al. 2009). Therefore, one could obtain, in the near future, the list of sRNAs that are essential under specific conditions, or for path- ogenesis of a given bacterium. The clinical significance of $S$. aureus sRNAs has been recently shown in human colonization and infection (Song et al. 2012). The expression levels of five sRNAs from $S$. aureus were shown to be highly variable in abscesses and in sputum samples of cystic fibrosis patients suggesting specific host responses. Conversely, they were highly uniform in the nasal carrier samples, which probably reflects the commensalism of $S$. aureus in this niche. This study also revealed that the expression of sRNAs in cells grown in rich medium culture does not uniformly mimic the in vivo conditions (Song et al. 2012). Therefore, the host response or the human microbiome may influence the expression pattern of sRNAs or vice versa. This suggests that a Dual RNA-seq approach on the host and pathogen will provide a more comprehensive view of the gene expression changes occurring in both the pathogen and the host (Westermann et al. 2012). Another interesting issue would be to search for secreted bacterial sRNAs, which could act as signaling molecules or perturb the host response. A recent study has shown that efficient cytosolic immune sensing requires the release of RNA and DNA from live Listeria to the cytoplasm of infected cells (Abdullah et al. 2012). These secreted bacterial RNA/DNA were recognized by the cytosolic sensors to trigger interferon $\beta$ production and to cause inflammasome activation.

Clearly we are only beginning to fully understand the roles of sRNAs in bacterial pathogenesis and persistence. Continued characterization of the functions, structures, and mechanism of action of individual sRNAs and their machineries will help us to fully understand the regulatory circuits that enable the bacteria to survive within the host and to cause disease.

Recent observations suggest that the Crc protein is devoid of RNA-binding activity and might act together with Hfq (Milojevic et al. 2013). From the genetic data, Crc counteracts the action of the small ncRNA CrcZ/Y, but experimental work is further required to reveal whether Crc is acting indirectly through Hfq or not. Regarding the recently reported aminoglycoside-binding riboswitch, Roth and Breaker 
(2013) have debated the physiological role of this RNA element with respect to its potential antibiotic sensing. There have been recent new findings related to the small RNA activities illustrated in this article. SgrS RNA (Fig. 2B) was revealed to function as an activator in addition to its known repressor functions (Papenfort et al. 2013b). The Qrr sRNAs (Fig. 3) have been found to control an unexpected large suite of new mRNA targets (Shao et al. 2013).

\section{ACKNOWLEDGMENTS}

We thank all the members of our respective laboratories for stimulating discussions, and Stan Gorski for help with the manuscript. This work is supported by the Federal Ministry of Education, Science, Research and Technology (BMBF NGFN, grant 01 GS0806 to J.V.), the German Research Council Priority Programmes SPP1258 (grant Vo857/4-2 to J.V.) and TRR34 (project B04 to J.V.), the "Centre National de la Recherche Scientifique" (CNRS to P.R.), the "Agence Nationale pour la Recherche" (ANR10-Pathogenomics-ARMSA to P.R.), and the labex Net RNA (ANR-10-LABX-36 to P.R.).

\section{REFERENCES}

Abdullah Z, Schlee M, Roth S, Mraheil MA, Barchet W, Bottcher J, Hain T, Geiger S, Hayakawa Y, Fritz JH, et al. 2012. RIG-I detects infection with live Listeria by sensing secreted bacterial nucleic acids. EMBO J 31: $4153-$ 4164.

Ansong C, Yoon H, Porwollik S, Mottaz-Brewer H, Petritis BO, Jaitly N, Adkins JN, McClelland M, Heffron F, Smith RD. 2009. Global systems-level analysis of Hfq and SmpB deletion mutants in Salmonella: Implications for virulence and global protein translation. PLOS ONE 4: e4809.

Argaman L, Hershberg R, Vogel J, Bejerano G, Wagner EG, Margalit H, Altuvia S. 2001. Novel small RNA-encoding genes in the intergenic regions of Escherichia coli. Curr Biol 11: 941-950.

Babitzke P, Baker CS, Romeo T. 2009. Regulation of translation initiation by RNA binding proteins. Annu Rev Microbiol 63: 27-44.

Balaban N, Novick RP. 1995. Translation of RNAIII, the Staphylococcus aureus agr regulatory RNA molecule, can be activated by a $3^{\prime}$ end deletion. FEMS Microbiol Lett 133: 155-161.

Bandyra KJ, Said N, Pfeiffer V, Gorna MW, Vogel J, Luisi BF. 2012. The seed region of a small RNA drives the con- trolled destruction of the target mRNA by the endoribonuclease RNase E. Mol Cell 47: 943-953.

Bardill JP, Zhao X, Hammer BK. 2011. The Vibrio cholerae quorum sensing response is mediated by Hfq-dependent sRNA/mRNA base pairing interactions. Mol Microbiol 80: $1381-1394$.

Barrick JE, Breaker RR. 2007. The distributions, mechanisms, and structures of metabolite-binding riboswitches. Genome Biol 8: R239.

Beaume M, Hernandez D, Farinelli L, Deluen C, Linder P, Gaspin C, Romby P, Schrenzel J, Francois P. 2010. Cartography of methicillin-resistant S. aureus transcripts: Detection, orientation and temporal expression during growth phase and stress conditions. PLOS ONE 5: e10725.

Beisel CL, Storz G. 2011. Discriminating tastes: Physiological contributions of the Hfq-binding small RNA Spot 42 to catabolite repression. RNA Biol 8: 766-770.

Bellows LE, Koestler BJ, Karaba SM, Waters CM, Lathem WW. 2012. Hfq-dependent, co-ordinate control of cyclic diguanylate synthesis and catabolism in the plague pathogen Yersinia pestis. Mol Microbiol 86: 661-674.

Blount KF, Wang JX, Lim J, Sudarsan N, Breaker RR. 2006. Antibacterial lysine analogs that target lysine riboswitches. Nat Chem Biol 3: 44-49.

Bohme K, Steinmann R, Kortmann J, Seekircher S, Heroven AK, Berger E, Pisano F, Thiermann T, Wolf-Watz H, Narberhaus F, et al. 2012. Concerted actions of a thermo-labile regulator and a unique intergenic RNA thermosensor control Yersinia virulence. PLoS Pathog 8: e1002518.

Bohn C, Rigoulay C, Chabelskaya S, Sharma CM, Marchais A, Skorski P, Borezee-Durant E, Barbet R, Jacquet E, Jacq A, et al. 2010. Experimental discovery of small RNAs in Staphylococcus aureus reveals a riboregulator of central metabolism. Nucleic Acids Res 38: 6620-6636.

Boisset S, Geissmann T, Huntzinger E, Fechter P, Bendridi N, Possedko M, Chevalier C, Helfer AC, Benito Y, Jacquier A, et al. 2007. Staphylococcus aureus RNAIII coordinately represses the synthesis of virulence factors and the transcription regulator Rot by an antisense mechanism. Genes Dev 21: 1353-1366.

Bossi L, Schwartz A, Guillemardet B, Boudvillain M, Figueroa-Bossi N. 2012. A role for Rho-dependent polarity in gene regulation by a noncoding small RNA. Genes Dev 26: $1864-1873$.

Bradley ES, Bodi K, Ismail AM, Camilli A. 2011. A genomewide approach to discovery of small RNAs involved in regulation of virulence in Vibrio cholerae. PLoS Pathog 7: e1002126.

Breaker RR. 2009. Riboswitches: From ancient gene-control systems to modern drug targets. Future Microbiol 4: 771773.

Breaker RR. 2011. Prospects for riboswitch discovery and analysis. Mol Cell 43: 867-879.

Brencic A, McFarland KA, McManus HR, Castang S, Mogno I, Dove SL, Lory S. 2009. The GacS/GacA signal transduction system of Pseudomonas aeruginosa acts exclusively through its control over the transcription of the RsmY and RsmZ regulatory small RNAs. Mol Microbiol 73: $434-445$. 
I. Caldelari et al.

Caldelari I, Fechter P, Lioliou E, Romilly C, Chevalier C Gaspin C, Romby P. 2011. A current overview of regulatory RNAs in Staphylococcus aureus. In Regulatory RNAs in prokaryotes (ed. Marchfelder A, Hess W), pp. 51-75. Wiley, New York.

Chao Y, Vogel J. 2010. The role of Hfq in bacterial pathogens. Curr Opin Microbiol 13: 24-33.

Chao Y, Papenfort K, Reinhardt R, Sharma CM, Vogel J. 2012. An atlas of Hfq-bound transcripts reveals $3^{\prime}$ UTRs as a genomic reservoir of regulatory small RNAs. EMBO J 31: 4005-4019.

Chevalier C, Boisset S, Romilly C, Masquida B, Fechter P, Geissmann T, Vandenesch F, Romby P. 2010. Staphylococcus aureus RNAIII binds to two distant regions of coa mRNA to arrest translation and promote mRNA degradation. PLoS Pathog 6: e1000809.

Condon C, Bechhofer DH. 2011. Regulated RNA stability in the Gram positives. Curr Opin Microbiol 14: 148-154.

Dambach MD, Winkler WC. 2009. Expanding roles for metabolite-sensing regulatory RNAs. Curr Opin Microbiol 12: $161-169$.

Davies BW, Bogard RW, Young TS, Mekalanos JJ. 2012. Coordinated regulation of accessory genetic elements produces cyclic di-nucleotides for $V$. cholerae virulence. Cell 149: $358-370$.

Faucher SP, Friedlander G, Livny J, Margalit H, Shuman HA. 2010. Legionella pneumophila 6S RNA optimizes intracellular multiplication. Proc Natl Acad Sci 107: 7533-7538.

Felden B, Vandenesch F, Bouloc P, Romby P. 2011. The Staphylococcus aureus RNome and its commitment to virulence. PLoS Pathog 7: e1002006.

Figueroa-Bossi N, Valentini M, Malleret L, Fiorini F, Bossi L. 2009. Caught at its own game: Regulatory small RNA inactivated by an inducible transcript mimicking its target. Genes Dev 23: 2004-2015.

Gefen O, Balaban NQ. 2009. The importance of being persistent: Heterogeneity of bacterial populations under antibiotic stress. FEMS Microbiol Rev 33: 704-717.

Geisinger E, Adhikari RP, Jin R, Ross HF, Novick RP. 2006. Inhibition of rot translation by RNAIII, a key feature of agr function. Mol Microbiol 61: 1038-1048.

Gogol EB, Rhodius VA, Papenfort K, Vogel J, Gross CA. 2011. Small RNAs endow a transcriptional activator with essential repressor functions for single-tier control of a global stress regulon. Proc Natl Acad Sci 108: 1287512880.

Gottesman S, Storz G. 2011. Bacterial small RNA regulators: Versatile roles and rapidly evolving variations. Cold Spring Harb Perspect Biol 3: a003798.

Grantcharova N, Peters V, Monteiro C, Zakikhany K, Romling U. 2010. Bistable expression of CsgD in biofilm development of Salmonella enterica serovar typhimurium. J Bacteriol 192: 456-466.

Gripenland J, Netterling S, Loh E, Tiensuu T, Toledo-Arana A, Johansson J. 2010. RNAs: Regulators of bacterial virulence. Nat Rev Microbiol 8: 857-866.

Heurlier K, Williams F, Heeb S, Dormond C, Pessi G, Singer D, Camara M, Williams P, Haas D. 2004. Positive control of swarming, rhamnolipid synthesis, and lipase production by the posttranscriptional RsmA/RsmZ system in
Pseudomonas aeruginosa PAO1. J Bacteriol 186: 2936 2945.

Hoe NP, Goguen JD. 1993. Temperature sensing in Yersinia pestis: Translation of the LcrF activator protein is thermally regulated. J Bacteriol 175: 7901-7909.

Horstmann N, Orans J, Valentin-Hansen P, Shelburne SAR, Brennan RG. 2012. Structural mechanism of Staphylococcus aureus Hfq binding to an RNA A-tract. Nucleic Acids Res 40: 11023-11035.

Huntzinger E, Boisset S, Saveanu C, Benito Y, Geissmann A, Namane G, Lina J, Etienne B, Ehresmann C, Ehresmann, et al. 2005. Staphylococcus aureus RNAIII and the endoribonuclease III coordinately regulate spa gene expression. EMBO J 24: 824-835.

Jacob AI, Köhrer C, Davies BW, RajBhandary UL, Walker GC. 2013. Conserved bacterial RNase YbeY plays key roles in $70 \mathrm{~S}$ ribosome quality control and $16 \mathrm{~S}$ rRNA maturation. Mol Cell 49: 427-438.

Jia X, Zhang J, Sun W, He W, Jiang H, Chen D, Murchie AIL. 2013. Riboswitch control of aminoglycoside antibiotic resistance. Cell 152: 68-81.

Johansson J, Mandin P, Renzoni A, Chiaruttini C, Springer M, Cossart P. 2002. An RNA thermosensor controls expression of virulence genes in Listeria monocytogenes. Cell 110: $551-561$.

Jousselin A, Metzinger L, Felden B. 2009. On the facultative requirement of the bacterial RNA chaperone, Hfq. Trends Microbiol 17: 399-405.

Kay E, Dubuis C, Haas D. 2005. Three small RNAs jointly ensure secondary metabolism and biocontrol in Pseudomonas fluorescens CHA0. Proc Natl Acad Sci 102: 17136 17141.

Klinkert B, Narberhaus F. 2009. Microbial thermosensors. Cell Mol Life Sci 66: 2661-2676.

Kortmann J, Narberhaus F. 2012. Bacterial RNA thermometers: Molecular zippers and switches. Nat Rev Microbiol 10: $255-265$.

Kröger C, Dillon SC, Cameron AD, Papenfort K, Sivasankaran SK, Hokamp K, Chao Y, Sittka A, Hebrard M, Handler K, et al. 2012. The transcriptional landscape and small RNAs of Salmonella enterica serovar Typhimurium. Proc Natl Acad Sci 109: E1277-E1286.

Langridge GC, Phan MD, Turner DJ, Perkins TT, Parts L, Haase J, Charles I, Maskell DJ, Peters SE, Dougan G, et al. 2009. Simultaneous assay of every Salmonella Typhi gene using one million transposon mutants. Genome Res 19: 2308-2316.

Lapouge K, Schubert M, Allain FH, Haas D. 2008. Gac/Rsm signal transduction pathway of $\gamma$-proteobacteria: From RNA recognition to regulation of social behaviour. $\mathrm{Mol}$ Microbiol 67: 241-253.

Lasa I, Toledo-Arana A, Dobin A, Villanueva M, de Los Mozos IR, Vergara-Irigaray M, Segura V, Fagegaltier D, Penades JR, Valle J, et al. 2011. Genome-wide antisense transcription drives mRNA processing in bacteria. Proc Natl Acad Sci 108: 20172-20177.

Lee EJ, Groisman EA. 2010. An antisense RNA that governs the expression kinetics of a multifunctional virulence gene. Mol Microbiol 76: 1020-1033. 
Lee EJ, Groisman EA. 2012a. Control of a Salmonella virulence locus by an ATP-sensing leader messenger RNA. Nature 486: 271-275.

Lee EJ, Groisman EA. 2012b. Tandem attenuators control expression of the Salmonella mgtCBR virulence operon. Mol Microbiol 86: 212-224.

Lee ER, Blount KF, Breaker RR. 2009. Roseoflavin is a natural antibacterial compound that binds to FMN riboswitches and regulates gene expression. RNA Biol 6: 187-194.

Lee ER, Baker JL, Weinberg Z, Sudarsan N, Breaker RR. 2010. An allosteric self-splicing ribozyme triggered by a bacterial second messenger. Science 329: 845-848.

Lenz DH, Miller MB, Zhu J, Kulkarni RV, Bassler BL. 2005. CsrA and three redundant small RNAs regulate quorum sensing in Vibrio cholerae. Mol Microbiol 58: 1186-1202.

Lioliou E, Sharma CM, Caldelari I, Helfer AC, Fechter P, Vandenesch F, Vogel J, Romby P. 2012. Global regulatory functions of the Staphylococcus aureus endoribonuclease iii in gene expression. PLoS Genet 8: e1002782.

Loh E, Dussurget O, Gripenland J, Vaitkevicius K, Tiensuu T, Mandin P, Repoila F, Buchrieser C, Cossart P, Johansson J. 2009. A trans-acting riboswitch controls expression of the virulence regulator PrfA in Listeria monocytogenes. Cell 139: 770-779.

Mandal M, Boese B, Barrick JE, Winkler WC, Breaker RR. 2003. Riboswitches control fundamental biochemical pathways in Bacillus subtilis and other bacteria. Cell 113: $577-586$

Mandlik A, Livny J, Robins WP, Ritchie JM, Mekalanos JJ, Waldor MK. 2011. RNA-Seq-based monitoring of infection-linked changes in Vibrio cholerae gene expression. Cell Host Microbe 10:165-174.

Mann B, van Opijnen T, Wang J, Obert C, Wang YD, Carter R, McGoldrick DJ, Ridout G, Camilli A, Tuomanen EI, et al. 2012. Control of virulence by small RNAs in Streptococcus pneumoniae. PLoS Pathogen 8: e1002788.

Mansjö M, Johansson J. 2011. The riboflavin analog roseoflavin targets an FMN-riboswitch and blocks Listeria monocytogenes growth, but also stimulates virulence gene-expression and infection. RNA Biol 8: 674-680.

Marchfelder A, Hess W. 2011. Regulatory RNAs in prokaryotes (ed. Marchfelder A, Hess W), pp. 1-253. Springer, New York.

Marzi S, Romby P. 2012. RNA mimicry, a decoy for regulatory proteins. Mol Microbiol 83: 1-6.

Mellin JR, Cossart P. 2012. The non-coding RNA world of the bacterial pathogen Listeria monocytogenes. RNA Biol 9: 372-378.

Milojevic T, Grishkovskaya I, Sonntleitner E, DjinovicCarugo K, Blasi U. 2013. The Pseudomonas aeruginosa catabolite repression control protein $\mathrm{Crc}$ is devoid of RNA binding activity. PloS ONE 23: e64609.

Monteiro C, Papenfort K, Hentrich K, Ahmad I, Le Guyon S, Reimann R, Grantcharova N, Romling U. 2012. Hfq and Hfq-dependent small RNAs are major contributors to multicellular development in Salmonella enterica serovar Typhimurium. RNA Biol 9: 489-502.

Moreno R, Marzi S, Romby P, Rojo F. 2009. The Crc global regulator binds to an unpaired A-rich motif at the Pseudomonas putida alkS mRNA coding sequence and inhib- its translation initiation. Nucleic Acids Res 37: $7678-$ 7690 .

Moreno R, Fonseca P, Rojo F. 2012. Two small RNAs, CrcY and $\mathrm{CrcZ}$, act in concert to sequester the Crc global regulator in Pseudomonas putida, modulating catabolite repression. Mol Microbiol 83: 24-40.

Morfeldt E, Taylor D, von Gabain A, Arvidson S. 1995. Activation of $\alpha$-toxin translation in Staphylococcus aureus by the trans-encoded antisense RNA, RNAIII. EMBO J 14: 4569-4577.

Morrison JM, Anderson KL, Beenken KE, Smeltzer MS, Dunman PM. 2012. The staphylococcal accessory regulator, SarA, is an RNA-binding protein that modulates the mRNA turnover properties of late-exponential and stationary phase Staphylococcus aureus cells. Front Cell Infect Microbiol 2: 1-11.

Mulhbacher J, Brouillette E, Allard M, Fortier LC, Malouin F, Lafontaine DA. 2010a. Novel riboswitch ligand analogs as selective inhibitors of guanine-related metabolic pathways. PLoS Pathog 6: e1000865.

Mulhbacher J, St-Pierre P, Lafontaine DA. 2010b. Therapeutic applications of ribozymes and riboswitches. Curr Opin Pharmacol 10: 551-556.

Narberhaus F. 2010. Translational control of bacterial heat shock and virulence genes by temperature-sensing mRNAs. RNA Biol 7: 84-89.

Nechooshtan G, Elgrably-Weiss M, Sheaffer A, Westhof E, Altuvia S. 2009. A pH-responsive riboregulator. Genes Dev 23: 2650-2662.

Ng WL, Bassler BL. 2009. Bacterial quorum-sensing network architectures. Annu Rev Genet 43: 197-222.

Nielsen JS, Larsen MH, Lillebaek EM, Bergholz TM, Christiansen $\mathrm{MH}$, Boor KJ, Wiedmann M, Kallipolitis BH 2011. A small RNA controls expression of the chitinase ChiA in Listeria monocytogenes. PLoS ONE 6: e19019.

Novick RP. 2003. Autoinduction and signal transduction in the regulation of staphylococcal virulence. Mol Microbiol 48: 1429-1449.

Novick RP, Geisinger E. 2008. Quorum sensing in Staphylococci. Annu Rev Genet 42: 541-564.

Obana N, Shirahama Y, Abe K, Nakamura K. 2010. Stabilization of Clostridium perfringens collagenase mRNA by VR-RNA-dependent cleavage in $5^{\prime}$ leader sequence. $\mathrm{Mol}$ Microbiol 77: 1416-1428.

Oliver HF, Orsi RH, Ponnala L, Keich U, Wang W, Sun Q, Cartinhour SW, Filiatrault MJ, Wiedmann M, Boor KJ. 2009. BMC Genomics 10: 641-663.

Padalon-Brauch G, Hershberg R, Elgrably-Weiss M, Baruch K, Rosenshine I, Margalit H, Altuvia S. 2008. Small RNAs encoded within genetic islands of Salmonella typhimurium show host-induced expression and role in virulence. Nucleic Acids Res 36: 1913-1927.

Pandey SP, Minesinger BK, Kumar J, Walker GC. 2011. A highly conserved protein of unknown function in Sinorhizobium meliloti affects sRNA regulation similar to Hfq. Nucleic Acids Res 39: 4691-4708.

Papenfort K, Vogel J. 2010. Regulatory RNA in bacterial pathogens. Cell Host Microbe 8: 116-127.

Papenfort K, Said N, Welsink T, Lucchini S, Hinton JC, Vogel J. 2009. Specific and pleiotropic patterns of mRNA reg- 
I. Caldelari et al.

ulation by ArcZ, a conserved, Hfq-dependent small RNA Mol Microbiol 74: 139-158.

Papenfort K, Bouvier M, Mika F, Sharma CM, Vogel J. 2010. Evidence for an autonomous $5^{\prime}$ target recognition domain in an Hfa-associated small RNA. Proc Natl Acad Sci 107: 20435-20440.

Papenfort K, Podkaminski D, Hinton JC, Vogel J. 2012. The ancestral SgrS RNA discriminates horizontally acquired Salmonella mRNAs through a single G-U wobble pair. Proc Natl Acad Sci 109: E757-E764.

Papenfort K, Corcoran C, Gupta SK, Miyakoshi M, Heidrich N, Chao Y, Frölich KS, Sharma CM, Ziebuhr W, Böhm A et al. 2013a. Regulatory mechanisms of special significance: Role of small RNAs in virulence regulation. In Regulation of bacterial virulence (ed. Vasil M, Darwin A), pp. 492-527. ASM, Washington, DC.

Papenfort K, Sun Y, Miyakoshi M, Vanderpool CK, Vogel J. 2013b. Small RNA-mediated activation of sugar phosphatase mRNA regulates glucose homeostasis. Cell 153: 426-437.

Pedrolli DB, Matern A, Wang J, Ester M, Siedler K, Breaker R, Mack M. 2012. A highly specialized flavin mononucleotide riboswitch responds differently to similar ligands and confers roseoflavin resistance to Streptomyces davawensis. Nucleic Acids Res 40: 8662-8673.

Pfeiffer V, Papenfort K, Lucchini S, Hinton JC, Vogel J. 2009. Coding sequence targeting by MicC RNA reveals bacterial mRNA silencing downstream of translational initiation. Nat Struct Mol Biol 16: 840-846.

Ramesh A, Winkler WC. 2010. Magnesium-sensing riboswitches in bacteria. RNA Biol 7: 77-83.

Ramirez-Pena E, Trevino J, Liu Z, Perez N, Sumby P. 2010 The group A Streptococcus small regulatory RNA FasX enhances streptokinase activity by increasing the stability of the ska mRNA transcript. Mol Microbiol 78: 1332 1347.

Rice JB, Balasubramanian D, Vanderpool CK. 2012. Small RNA binding-site multiplicity involved in translational regulation of a polycistronic mRNA. Proc Natl Acad Sci 109: E2691-E2698.

Richard AL, Withey JH, Beyhan S, Yildiz F, DiRita VJ. 2010. The Vibrio cholerae virulence regulatory cascade controls glucose uptake through activation of TarA, a small regulatory RNA. Mol Microbiol 78: 1171-1181.

Roberts C, Anderson KL, Murphy E, Projan SJ, Mounts W, Hurlburt B, Smeltzer M, Overbeek R, Disz T, Dunman PM. 2006. Characterizing the effect of the Staphylococcus aureus virulence factor regulator, SarA, on log-phase mRNA half-lives. J Bacteriol 188: 2593-2603.

Rojo F. 2010. Carbon catabolite repression in Pseudomonas: Optimizing metabolic versatility and interactions with the environment. FEMS Microbiol Rev 34: 658-684.

Romby P, Charpentier E. 2010. An overview of RNAs with regulatory functions in Gram-positive bacteria. Cell Mol Life Sci 67: 217-237.

Romeo T, Vakulskas CA, Babitzke P. 2012. Post-transcriptional regulation on a global scale: Form and function of Csr/Rsm systems. Environ Microbiol 15: 313-324.

Romilly C, Caldelari I, Parmentier D, Lioliou E, Romby P, Fechter P. 2012. Current knowledge on regulatory RNAs and their machineries in Staphylococcus aureus. RNA Biol 9: 402-413.

Roth A, Breaker RR. 2013. Integron attIl sites, not riboswitches, associate with antibiotic resistance genes. Cell 153: $1417-1418$.

Rutherford ST, van Kessel JC, Shao Y, Bassler BL. 2011. AphA and LuxR/HapR reciprocally control quorum sensing in vibrios. Genes Dev 25: 397-408.

Santiviago CA, Reynolds MM, Porwollik S, Choi SH, Long F Andrews-Polymenis HL, McClelland M. 2009. Analysis of pools of targeted Salmonella deletion mutants identifies novel genes affecting fitness during competitive infection in mice. PLoS Pathog 5: e1000477.

Sayed N, Jousselin A, Felden B. 2011. A cis-antisense RNA acts in trans in Staphylococcus aureus to control translation of a human cytolytic peptide. Nat Struct Mol Biol 19: $105-112$.

Serganov A. 2010. Determination of riboswitch structures: Light at the end of the tunnel? RNA Biol 7: 98-103.

Serganov A, Nudler E. 2013. A decade of riboswitches. Cell 152: $17-24$.

Sesto N, Wurtzel O, Archambaud C, Sorek R, Cossart P. 2013. The excludon: A new concept in bacterial antisense RNA-mediated gene regulation. Nat Rev Microbiol 11: $75-82$.

Shao Y, Bassler BL. 2012. Quorum-sensing non-coding small RNAs use unique pairing regions to differentially control mRNA targets. Mol Microbiol 83: 599-611.

Shao Y, Feng L, Rutherford ST, Papenfort K, Bassler BL. 2013. Functional determinants of the quorum-sensing non-coding RNAs and their roles in target regulation. EMBO J 32: 2158-2171.

Sharma CM, Hoffmann S, Darfeuille F, Reignier J, Findeiss S, Sittka A, Chabas S, Reiche K, Hackermüller J, Reinhardt R, et al. 2010. The primary transcriptome of the major human pathogen Helicobacter pylori. Nature 464: 250-255.

Sharma CM, Papenfort K, Pernitzsch SR, Mollenkopf HJ, Hinton JC, Vogel J. 2011. Pervasive post-transcriptional control of genes involved in amino acid metabolism by the Hfq-dependent GcvB small RNA. Mol Microbiol 81: $1144-1165$.

Sittka A, Lucchini S, Papenfort K, Sharma CM, Rolle K, Binnewies TT, Hinton JC, Vogel J. 2008. Deep sequencing analysis of small noncoding RNA and mRNA targets of the global post-transcriptional regulator, Hfq. PLoS Genet 4: e1000163.

Sittka A, Sharma CM, Rolle K, Vogel J. 2009. Deep sequencing of Salmonella RNA associated with heterologous Hfq proteins in vivo reveals small RNAs as a major target class and identifies RNA processing phenotypes. RNA Biol 6: 266-275.

Somerville GA, Proctor RA. 2009. At the crossroads of bacterial metabolism and virulence factor synthesis in staphylococci. Microbiol Mol Biol Rev 73: $233-$ 248.

Song T, Mika F, Lindmark B, Liu Z, Schild S, Bishop A, Zhu J, Camilli A, Johansson J, Vogel J, et al. 2008. A new Vibrio cholerae sRNA modulates colonization and affects release of outer membrane vesicles. Mol Microbiol 70: $100-111$. 
sRNA Regulation in Bacterial Pathogens

Song J, Lays C, Vandenesch F, Benito Y, Bes M, Chu Y, Lina G, Romby P, Geissmann T, Boisset S. 2012. The expression of small regulatory RNAs in clinical samples reflects the different life styles of Staphylococcus aureus in colonization vs. infection. PLoS ONE 7: e37294.

Sonnleitner E, Haas D. 2011. Small RNAs as regulators of primary and secondary metabolism in Pseudomonas species. Appl Microbiol Biotechnol 91: 63-79.

Sonnleitner E, Abdou L, Haas D. 2009. Small RNA as global regulator of carbon catabolite repression in Pseudomonas aeruginosa. Proc Natl Acad Sci 106: 21866-21871.

Sonnleitner E, Gonzalez N, Sorger-Domenigg T, Heeb S, Richter AS, Backofen R, Williams P, Huttenhofer A, Haas D, Blasi U. 2011. The small RNA PhrS stimulates synthesis of the Pseudomonas aeruginosa quinolone signal. Mol Microbiol 80: 868-885.

Storz G, Vogel J, Wassarman KM. 2011. Regulation by small RNAs in bacteria: Expanding frontiers. Mol Cell 43: 880891.

Sudarsan N, Cohen-Chalamish S, Nakamura S, Emilsson GM, Breaker RR. 2005. Thiamine pyrophosphate riboswitches are targets for the antimicrobial compound pyrithiamine. Chem Biol 12: 1325-1335.

Sudarsan N, Lee ER, Weinberg Z, Moy RH, Kim JN, Link KH, Breaker RR. 2008. Riboswitches in eubacteria sense the second messenger cyclic di-GMP. Science 321: $411-$ 413.

Toledo-Arana A, Dussurget O, Nikitas G, Sesto N, GuetRevillet H, Balestrino D, Loh E, Gripenland J, Tiensuu T, Vaitkevicius K, et al. 2009. The Listeria transcriptional landscape from saprophytism to virulence. Nature 459: 950-956.
Tu KC, Long T, Svenningsen SL, Wingreen NS, Bassler BL. 2010. Negative feedback loops involving small regulatory RNAs precisely control the Vibrio harveyi quorum-sensing response. Mol Cell 37: 567-579.

Vogel J, Luisi BF. 2011. Hfq and its constellation of RNA. Nat Rev Microbiol 9: 578-589.

Vogel J, Bartels V, Tang TH, Churakov G, Slagter-Jäger JG, Hüttenhofer A, Wagner EGH. 2003. RNomics in Escherichia coli detects new sRNA species and indicates parallel transcriptional output in bacteria. Nucleic Acids Res 31: 6435-6443.

Wadler CS, Vanderpool CK. 2007. A dual function for a bacterial small RNA: SgrS performs base pairing-dependent regulation and encodes a functional polypeptide. Proc Natl Acad Sci 104: 20454-20459.

Wassarman KM. 2007.6S RNA: A regulator of transcription. Mol Microbiol 65: 1425-1431.

Wassarman KM, Repoila F, Rosenow C, Storz G, Gottesman S. 2001. Identification of novel small RNAs using comparative genomics and microarrays. Genes Dev 15: 1637 1651.

Westermann AJ, Gorski SA, Vogel J. 2012. Dual RNA-seq of pathogen and host. Nat Rev Microbiol 10: 618-630.

Wurtzel O, Sesto N, Mellin JR, Karunker I, Edelheit S, Becavin C, Archambaud C, Cossart P, Sorek R. 2012. Comparative transcriptomics of pathogenic and non-pathogenic Listeria species. Mol Syst Biol 8: 583.

Yao Z, Barrick J, Weinberg Z, Neph S, Breaker R, Tompa M, Ruzzo WL. 2007. A computational pipeline for highthroughput discovery of cis-regulatory noncoding RNA in prokaryotes. PLoS Comput Biol 3: e126. 


\section{$\&_{\mathrm{CSH}}^{\infty} \&$ Cold Spring Harbor

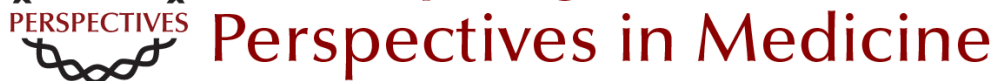

\section{RNA-Mediated Regulation in Pathogenic Bacteria}

Isabelle Caldelari, Yanjie Chao, Pascale Romby and Jörg Vogel

Cold Spring Harb Perspect Med 2013; doi: 10.1101/cshperspect.a010298

Subject Collection Bacterial Pathogenesis

Therapeutic and Prophylactic Applications of Bacteriophage Components in Modern Medicine Sankar Adhya, Carl R. Merril and Biswajit Biswas

Vaccines, Reverse Vaccinology, and Bacterial Pathogenesis Isabel Delany, Rino Rappuoli and Kate L. Seib

Helicobacter and Salmonella Persistent Infection Strategies

Denise M. Monack

Echoes of a Distant Past: The cag Pathogenicity Island of Helicobacter pylori

Nicola Pacchiani, Stefano Censini, Ludovico Buti, et al.

RNA-Mediated Regulation in Pathogenic Bacteria Isabelle Caldelari, Yanjie Chao, Pascale Romby, et al.

The Pneumococcus: Epidemiology, Microbiology, and Pathogenesis

Birgitta Henriques-Normark and Elaine I. Tuomanen

Pathogenesis of Meningococcemia

Mathieu Coureuil, Olivier Join-Lambert, Hervé

Lécuyer, et al.

Chlamydial Intracellular Survival Strategies

Robert J. Bastidas, Cherilyn A. Elwell, Joanne N. Engel, et al.
Mechanisms and Biological Roles of

Contact-Dependent Growth Inhibition Systems

Christopher S. Hayes, Sanna Koskiniemi, Zachary

C. Ruhe, et al.

A Genome-Wide Perspective of Human Diversity and Its Implications in Infectious Disease Jérémy Manry and Lluis Quintana-Murci

Host Specificity of Bacterial Pathogens Andreas Bäumler and Ferric C. Fang

The Inside Story of Shigella Invasion of Intestinal Epithelial Cells

Nathalie Carayol and Guy Tran Van Nhieu

Bartonella and Brucella--Weapons and Strategies for Stealth Attack

Houchaima Ben-Tekaya, Jean-Pierre Gorvel and Christoph Dehio

Concepts and Mechanisms: Crossing Host

Barriers

Kelly S. Doran, Anirban Banerjee, Olivier Disson, et al.

Genome Dynamics in Legionella: The Basis of

Versatility and Adaptation to Intracellular

Replication

Laura Gomez-Valero and Carmen Buchrieser

Mechanisms of Francisella tularensis Intracellular

Pathogenesis

Jean Celli and Thomas C. Zahrt

For additional articles in this collection, see http://perspectivesinmedicine.cshlp.org/cgi/collection/ 